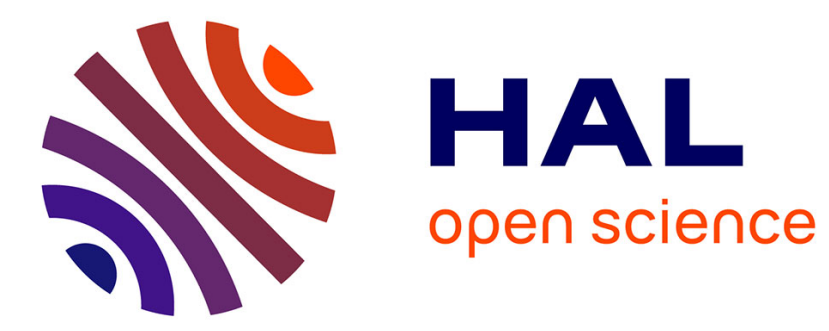

\title{
Impacts of a French Urban Renewal Program on Local Housing Markets
}

Sylvain Chareyron, Florence Goffette-Nagot, Lucie Letrouit

\section{To cite this version:}

Sylvain Chareyron, Florence Goffette-Nagot, Lucie Letrouit. Impacts of a French Urban Renewal Program on Local Housing Markets. 2020. halshs-02972448

\section{HAL Id: halshs-02972448 \\ https://shs.hal.science/halshs-02972448}

Preprint submitted on 20 Oct 2020

HAL is a multi-disciplinary open access archive for the deposit and dissemination of scientific research documents, whether they are published or not. The documents may come from teaching and research institutions in France or abroad, or from public or private research centers.
L'archive ouverte pluridisciplinaire HAL, est destinée au dépôt et à la diffusion de documents scientifiques de niveau recherche, publiés ou non, émanant des établissements d'enseignement et de recherche français ou étrangers, des laboratoires publics ou privés. 


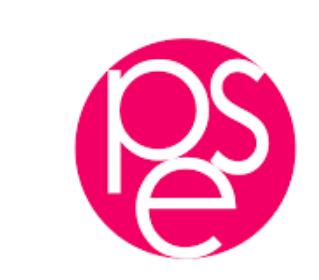

PARISSCHOOL OF ECONOMICS
ECOLE D'ECONOMIE DE PARIS

WORKING PAPER № 2020 - 64

Impacts of a French Urban Renewal

Program on Local Housing Markets

\section{Sylvain Chareyron}

Florence Goffette-Nagot

Lucie Letrouit

JEL Codes: D62, H23, R21, R31

Keywords: Place-based policies, urban renewal, housing prices, housing spillovers, difference-indifferences

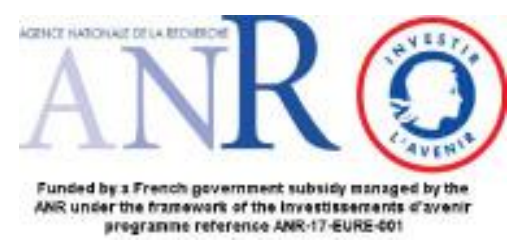




\title{
Impacts of a French Urban Renewal Program on Local Housing Markets
}

\author{
Sylvain Chareyron ${ }^{1}$ \\ Florence Goffette-NAGOT ${ }^{2}$
}

LuCIE LETROUit ${ }^{3}$

September 28, 2020

\begin{abstract}
Urban renewal programs have been implemented in many countries to fight housing decay, poverty concentration, and associated social ills in the last decades. In this paper, we propose an evaluation of a large-scale urban renewal program launched in France in 2004. Using a novel estimator aimed at avoiding bias in the estimation of treatment effects heterogeneous across treatment groups or time periods, and complementing its results with a more precise double fixed effects difference-in-differences estimator, we find no significant effect of the program on housing values and transaction volume. However, we do find a significant impact on the social profile of housing buyers and sellers: an increased number of upward transitions of housing units, from blue-collar sellers to intermediate category buyers or from intermediate category sellers to executive buyers, and reduced housing transactions among executives. Altogether, our findings suggest a renewed interest of upper socio-professional categories to invest or keep their property in the renovated neighborhoods. ${ }^{4}$
\end{abstract}

Keywords: Place-based policies, urban renewal, housing prices, housing spillovers, difference-indifferences

JEL classification: D62, H23, R21, R31

\footnotetext{
${ }^{1}$ Université Paris-Est Créteil, ERUDITE, TEPP, sylvain.chareyron@univ-paris-est.fr

${ }^{2}$ Université de Lyon, GATE, CNRS, goffette-nagot@gate.cnrs.fr

${ }^{3}$ Paris School of Economics, Ecole des Ponts ParisTech. Corresponding author: Lucie Letrouit, 48 boulevard Jourdan 75014 PARIS, lucie.letrouit@psemail.eu

${ }^{4}$ We are grateful to Gilles Duranton, Stephan Heblich, Camille Hémet, Miren Lafourcade and David Margolis for useful comments and suggestions, as well as to the participants to the EEA 2020, UEA Philadelphia 2019, EALE 2019, JMA 2019, AFSE 2019 conferences, the Munich Young Economists' Meetings 2019 and 2019 PPCR workshop and to the audience of the Lunch Seminar at the ERUDITE laboratory, the Lunch Seminar at GATE and the Labor and Public Economics Seminar of the Paris School of Economics. This paper also benefited from exchanges with Clément de Chaisemartin and Xavier d'Haultfœuille. This research benefited from funding from the Labex OSE, from the Chaire "Habiter ensemble la ville de demain", as part of Labex Intelligences des Mondes Urbains (IMU), University of Lyon, and from the Chaire of the Ministry for the Ecological and Solidary Transition (MTES), which we all grafully aknowledge. Last but not least, we thank the MTES, the CGET and the ANRU, which gave us access to the data necessary to this research.
} 


\section{Introduction}

Urban renewal programs have been implemented in many countries in the last decades to fight housing decay, poverty concentration and associated social ills. ${ }^{5}$ However, compared to other placebased policies, such as Enterprise Zones programs (see Papke, 1993; Neumark and Simpson, 2015 for surveys) or place-based subsidies to housing investments as LIHTC (Baum-Snow and Marion, 2009; Eriksen and Rosenthal, 2010), only few empirical studies of their impacts have been conducted and the results are mitigated. The outcomes of interest are mainly population social composition, housing prices as a signal of attractivity, or crime rate. Some studies have found positive effects of renovation on housing prices (Galster et al., 2006; Rossi-Hansberg et al., 2010; Collins and Shester, 2013; Koster and Van Ommeren, 2019), but others have found limited (Ding et al., 2000; Aarland et al., 2017) or insignificant (Barthélémy et al., 2007; Ahlfeldt et al., 2017) effects of these programs. The pattern is similar for impacts on household income, employment or poverty rate (Van Beckhoven and Van Kempen, 2003; Collins and Shester, 2013; Guyon, 2017; González-Pampillón et al., 2019). However, renewal programs seem to have had positive outcomes on crime (Aliprantis and Hartley, 2015; Alonso et al., 2019).

Analyses of urban renovation programs have often focused on city-level programs or state-level programs of moderate magnitudes (Ahlfeldt et al., 2017; Rossi-Hansberg et al., 2010; Barthélémy et al., 2007). To our knowledge, only three studies of large nationwide renewal programs have been conducted. A large-scale U.S. federal program has been studied by Collins and Shester (2013), but it was conducted more than 45 years ago and its effects were only investigated at the city level. Aliprantis and Hartley (2015) consider the impact of the U.S. program HOPE VI on crime, but only within the city of Chicago. Koster and Van Ommeren (2019) consider the overall impact of a nationwide renewal program, with however a limited level of financing of about $€ 1$ billion invested between 2007 and 2012 .

In this paper, we analyze the impacts of a large-scale French urban renewal program, the Programme National de Rénovation Urbaine (PNRU hereafter). This program launched in 2004 consisted mainly in the renovation, demolition and construction of public housing, and marginally in the improvement and creation of public facilities. Our aim is to explore its impact on the attractivity of the renovated neighborhoods by looking at changes in private housing markets. ${ }^{6}$ We thus evaluate the program's externalities and not its direct effects on the value of renovated public housing units. Our contribution is threefold. First, we take advantage of the exceptionally large scale of this program, which involved more than $€ 47$ billions investment and 594 neighborhoods located in about 150 different cities, to provide more reliable estimates. Indeed, the large number of control areas

\footnotetext{
${ }^{5}$ e.g. in the United States, the Netherlands, Spain, the United Kingdom, France.

${ }^{6}$ This type of positive amenity effect produced by policy intervention on the housing stock is also explored by Baum-Snow and Marion (2009).
} 
reduces the sensitivity of the counterfactual to unobserved shocks as shown by Ahlfeldt et al. (2017) and the large number of observations makes it possible to check the robustness of our main results on subsamples. Second, we use an estimator robust to potential treatment effect heterogeneity. Indeed, because renovation took place in very different contexts and started at different dates depending on the neighborhood, large heterogeneity in treatment effects across space and over time can be suspected. ${ }^{7}$ This heterogeneity is combined with imbalance in treatment status along these same two dimensions. To get unbiased estimates of the program's impacts in such a context, we apply the novel methodology proposed by De Chaisemartin and D'Haultfœuille (forthcoming) for this very purpose. To the best of our knowledge, our paper is one of the first papers using this methodology and the first to use it to estimate the impact of an urban renewal program. Third, our data allow us to analyze a rarely investigated dimension of urban renewal, namely the impact of renovation on sellers' and buyers' social category.

Our identification strategy relies on difference-in-differences, exploiting both the existence of never treated neighborhoods that were initially eligible, and staggered start of renovation across renovated neighborhoods. The identification assumption is that, conditional on fixed effects and controls, the trends in the outcomes under study would have been the same in never-renovated neighborhoods and in renovated ones in the absence of renovation. This hypothesis will be checked using estimates of dynamic treatment effects before the start of renovation. Furthermore, as for renovated neighborhoods, the history of the program exposed in the following shows that the set of renovated neighborhoods was chosen at the beginning of the program and the starting year of renovation was not decided depending on the evolution of housing prices in these neighborhoods.

Our results indicate that renovation did not lead to a significant increase in housing values on average in the treated neighborhoods in the time frame considered. The results appear to be stable accross subsamples defined to account for different treatment intensities, namely the level of funding per housing unit and the initial share of public housing, and for tension on the housing market, by separating renovated neighborhoods located in one of the four largest French urban units (Paris, Lyon, Marseille and Lille) from the others. ${ }^{8}$ They are also robust to various sensitivity tests. It is still possible that the program had a small impact on housing values, albeit sufficiently small not to be captured by our analysis. This impact is in any case below $3.5 \%$, the upperbound of the $95 \%$ confidence interval of our preferred estimate. We also find no impact on the volume of transactions. However, we do find that the program significantly affected the social profile of housing buyers and

\footnotetext{
${ }^{7}$ As an illustration, four renovated neighborhoods are located in Paris municipality, where tension on the housing market is extreme, and six additional neighborhoods are located less than 8 kilometers from Paris center, whereas renovation also took place in some economically distressed urban units where public housing offices asked the National Agency for Urban Renewal (ANRU) not to replace one-for-one the demolished public housing units because of a lack of housing demand (Le Monde, 2019).

${ }^{8}$ In the French statistical system, an urban unity is a municipality or a group of municipalities which includes a continuously built up zone (no cut of more than 200 meters between two constructions) with at least 2,000 inhabitants. We will also refer to urban units as cities.
} 
sellers in the renovated neighborhoods. Indeed, we find evidence that it led to an increased number of upward transitions of housing units, from a blue-collar seller to an intermediate category buyer or from an intermediate category seller to an executive buyer, and to a reduction of housing transactions among executives, suggesting an increased interest of upper socio-professional categories to invest in the renovated neighborhoods or to remain in them.

The following of the paper is organized as follows. Section 2 depicts the urban renewal program under study. Section 3 is dedicated to the presentation of the empirical strategy and Section 4 to the description of the data. We present our results in Section 5 and conclude in Section 6.

\section{The French National Urban Renewal Program}

The present research focuses on the consequences of the PNRU program launched in France in 2004. This program had four distinct goals: restructuring neighborhoods, increasing social diversity, supporting sustainable development of territories and reducing inequalities between places and between populations. To this aim, a list of eligible neighborhoods located in urban units on the whole French territory was established. It included all of the 751 neighborhoods referred to as Sensitive Urban Zones (hereafter ZUS) that were designated by the State between 1996 and 2000 as targets of the French urban policy, based on the existence of large public housing developements and low employment-to-population ratios. This list also defined 166 additional neighborhoods called "Article 6" selected according to similar criteria. These eligible neighborhoods exhibited high levels of poverty and degradation of their buildings.

Municipalities to which these neighborhoods belong were asked to build renovation projects in coordination with local actors, in particular public housing offices. These projects were then submitted to the National Agency for Urban Renewal (ANRU hereafter) that was created to ensure the administrative follow-up of urban renewal operations. The Agency, in some cases, asked for modifications of the renovation projects and then decided whether to grant funding. ${ }^{9}$ On the overall, $€ 47$ billions were invested from 2004 to 2020 in as many as 594 neighborhoods (see Figure A1 in Appendix for a map of the geographical distribution of funding at the departmental level). ${ }^{10,11}$ For the sake of brevity, we will use the term "urban policy neighborhoods" or even "neighborhoods" to designate the set of eligible neighborhoods, both ZUS and "Article 6" neighborhoods. As for treated

\footnotetext{
${ }^{9}$ From the information available on the PNRU program and our discussions with the Agency, it is not clear how local projects were selected for renovation in practice. Not all ZUS were proposed for renovation by local authorities. And there does not seem to have been a simple index score according to which neighborhoods were graded, as was the case for renovation programs in some other countries. This forbids using a regression-discontinuity design as in Alonso et al. (2019) or Koster and Van Ommeren (2019).

${ }^{10}$ The major contributors to the program were public housing officies, which provided about $€ 20.5$ billions. The ANRU comes next with around $€ 11.5$ billions. The remaining funding was given mainly by local authorities.

${ }^{11}$ By way of comparison, the Dutch program considered in Koster and Van Ommeren (2019) involved an investment of about $€ 1$ billion in 83 neighborhoods.
} 
neighborhoods, we simply speak of "renovated neighborhoods", be they observed before of after renovation started. ${ }^{12,13}$

The program affected directly close to 1 million dwellings, with 150,000 housing units demoslished, 135,000 built, 315,000 rehabilitated and 350,000 concerned by their building's rehabilitation (i.e. the beautification of public housing projects, with, for example, the setting up of a small front garden). A quarter of the budget was dedicated to the improvement of the urban environment and of public equipments and services, as well as economic and commercial spaces (ONZUS, 2013). Overall, an average of $€ 79$ millions was invested and 253 housing units destroyed in each renovated neighborhoods. This program contrasts with usual urban renewal programs studied in the literature, due not only to its large scale but also to the key role attributed to the massive demolition and reconstruction of public housing. Indeed, many large public housing developments erected in the post World War II era had strongly depreciated and were perceived as stigmatizing for these neighborhoods. They were demolished as a part of the PNRU local renovation plans.

\section{Empirical strategy}

In order to estimate the impacts of the PNRU program, we rely on a difference-in-differences strategy exploiting both the existence of never treated neighborhoods that were initially eligible, and staggered start of renovation across renovated neighborhoods. The traditional difference-in-differences estimation consists in using a double fixed effects estimator (DFE hereafter), where group fixed effects control for time-constant group heterogeneity, and time fixed effects control for general time trends. Under the assumption of common trends and with constant treatment effects, this strategy allows for the unbiased estimation of the average treatment effect.

However, recent papers considering staggered adoption designs, in which treatment of different groups starts at different times, have shown that the treatment effect estimated with a DFE regression is actually a weighted average of individual treatment effects, with weights that might be negative (Borusyak and Jaravel, 2017; Athey and Imbens, 2018; Goodman-Bacon, 2018; De Chaisemartin and D'Haultfœuille, forthcoming). If treatment effects are heterogeneous, then the DFEbased average treatment effect is likely to be biased. Moreover, De Chaisemartin and D'Haultfœuille (forthcoming) (hereafter DCDH) demonstrate that the DFE estimate is especially likely to involve negative weights and therefore give biased estimates if treatment effects differ between periods with

\footnotetext{
${ }^{12}$ All "Article 6" neighborhoods were renovated. In the analysis, we pool them with renovated ZUS, because they have quite similar socio-economic characteristics, and the transactions in "Article 6" neighborhoods are too scarce to allow for a separate analysis. They represent about $10 \%$ of all transactions in renovated neighborhoods in our sample.

${ }^{13}$ As an illustration of the different geographical scales at stake in this paper, Figure A2 represents the urban unit of Grenoble in the Rhône-Alpes region in France. It shows the borders of Grenoble municipality and of the three types of neighborhoods we are interested in: ZUS neighborhoods that were renovated ("ZUS-renov"), "Article 6" neighborhoods that were all renovated ("Art6-renov") and ZUS neighborhoods that were not renovated ("ZUS-norenov").
} 
many versus few treated groups, or between groups treated for many versus few periods. ${ }^{14}$ As we will show in the following, imbalance in treatment status across groups and time periods are present in the case of PNRU's impact on housing prices, as in many staggered adoption designs, and heterogeneity of treatment effects can be suspected.

To overcome a potential bias, DCDH propose an alternative estimator ( ID $_{M}$ in the following) that is robust to treatment effect heterogeneity across groups and time periods. This estimator consists in computing, at each time, a difference-in-differences based on switchers (i.e. groups of which treatment status changes at that time) as compared to groups with stable treatment. These differences-in-differences are then averaged over the whole observation period, with weights that depend on the number of switchers at each time.

In this section, we first describe how we implement the traditional DFE estimator, and then turn to the $\mathrm{DID}_{M}$ estimator, which corresponds to our preferred estimation, though we also present results based on the DFE estimator.

\subsection{Double fixed effects estimator}

To estimate the average treatment effect based on a DFE estimator, we use a hedonic regression in which the logarithm of the price of a housing transaction is regressed on the characteristics of the transacted housing unit and time trends at the urban unit level. A dummy indicates whether the housing unit is located in a neighborhood under renovation. Its coefficient is the estimate of the average time-constant effect of the renovation program on prices in renovated neighborhoods. In practice, the following equation is estimated:

$$
\log \left(P_{i t n u}\right)=\beta_{T} \mathbf{1}_{n \in \mathcal{R}, t-T(n) \geq 0}+\phi_{t}+\mu_{n}+X_{i t} \beta+\gamma_{u} t+\gamma_{u}^{\prime} t^{2}+\epsilon_{i t n u}
$$

where $i$ is the identifier of the housing unit, $t$ is the year of the transaction, $n$ is the neighborhood in which the housing unit is located, $u$ is its urban unit, $\mathcal{R}$ is the set of renovated neighborhoods, $T(n)$ is the date at which renovation was launched in neighborhood $n$ (if $n \in \mathcal{R}$ ), $\phi_{t}$ is a time fixed effect, $\mu_{n}$ is a neighborhood fixed effect, $\gamma_{u}$ (resp. $\gamma_{u}^{\prime}$ ) is the linear (resp. square) time trend of housing prices in urban unit $u \cdot{ }^{15} X_{i t}$ is a vector of characteristics of the transacted housing unit: the number of rooms interacted with an apartment or house indicator, number of bathrooms, period of construction, floor space per room, dummy equal to one if the dwelling is less than 5 years old, and distance of the transaction to the city center. In this specification, neighborhood fixed effects account for time-constant heterogeneity while urban units time trends and transacted housing units

\footnotetext{
${ }^{14}$ See also Borusyak and Jaravel (2017).

${ }^{15}$ The quadratic functional form is especially useful to account for the reversal of housing prices after the 2008's crisis, while keeping the number of estimated coefficients reasonable. We separate Paris commune from the rest of the Parisian urban unit in order to account for different time trends in the two areas.
} 
characteristics account for some time-varying heterogeneity.

Following Ahlfeldt et al. (2017), we also analyze the program's time-varying effects by introducing a time flexible structure into the previous equation:

$$
\log \left(P_{i t n u}\right)=\sum_{\Delta \in S} \beta_{\Delta} \mathbf{1}_{n \in \mathcal{R}, t-T(n) \in\{\Delta-1, \Delta\}}+\phi_{t}+\mu_{n}+X_{i t} \beta+\gamma_{u} t+\gamma_{u}^{\prime} t^{2}+\epsilon_{i t n u}
$$

In this time-varying specification, $\Delta \in S$, where $S=\{-11,-9,-7,-5,-3,-1,1,3,5,7,9,11\}$. Time-varying effects are grouped by pairs, because the dataset on housing prices is available only every even year. $\mathbf{1}_{n \in \mathcal{R}, t-T(n) \in\{\Delta-1, \Delta\}}$ is then a dummy function equal to one if and only if renovation in neighborhood $n$ started $\Delta-1$ or $\Delta$ years before the transaction. ${ }^{16}$ The reference for the computation of the program impacts are years $T(n)-2$ for neighborhoods where renovation started on an even year and $T(n)-1$ for neighborhoods where renovation started on an uneven year. $\beta_{\Delta}$ is then the effect of the program after $\Delta-1$ or $\Delta$ years.

We include in the sample the transactions that occured in an urban policy neighborhood. We exclude however transactions located less than 500 meters away from the border of a renovated neighborhood so as to avoid spillovers from a renovated neighborhood to a nearby non-renovated neighborhood. The set of control observations therefore consists of transactions in non-renovated urban policy neighborhoods outside of the 500 meter buffer around renovated neighborhoods. The inclusion of non-renovated urban policy neighborhoods as controls is the most natural, as renovated neighborhoods have been chosen among urban policy neighborhoods and are relatively similar (see Table 2 below for the descriptive statistics of renovated and non-renovated neighborhoods). In the robustness checks, we also employ matching and weighting procedures to make sure that the existing differences between the treated and control groups do not affect our estimates. Moreoever, given the staggered adoption design and our empirical specification, the identification of treatment effects also exploits transactions in renovated neighborhoods which occured before the start of renovation. The difference-in-differences method is based on the common trend hypothesis, which states that the evolution of housing prices should be the same in the non-renovated and renovated neighborhoods in the absence of renovation. In practice, this hypothesis is tested by verifying the absence of pre-trends, that is, the estimated $\beta_{\Delta}$ being not significantly different from 0 when $\Delta<0$.

We also estimate the impact of the program on the volume of transactions. To this aim, observations are aggregated at the level of neighborhoods and equations similar to Equations (1) and (2) are estimated, replacing the log price by the number of transactions in the neighborhood and suppressing housing unit characteristics. Eventually, because one of the aims of the PNRU program is to bring new social categories in renovated neighborhoods so as to foster a change in the social profile of their inhabitants, we also consider the PNRU's impacts on the socio-professional category of housing

\footnotetext{
${ }^{16}$ If $\Delta$ is negative, the dummy is equal to one when renovation started $|\Delta|$ or $|\Delta|+1$ years after the transaction.
} 
buyers and sellers, for which we similarly estimate a linear probability model of the probability for a housing buyer to be an executive (resp. a blue-collar, resp. intermediate professional category) or for a housing seller to be an executive (resp. blue-collar, resp. intermediate professional category). We therefore have six regressions corresponding to Equations (1) or (2), in which the outcome is a dummy equal to 1 if the housing buyer is an executive (resp. a blue-collar or intermediate category, resp. if the housing seller belongs to each of these categories) and in which the characteristics of the transacted housing unit have been removed, because they are themselves largely determined by the socio-professional category of the housing buyer or seller.

\section{$3.2 \quad \mathrm{DID}_{M}$ estimator}

As previously explained, the DFE estimator is likely to yield biased estimates if treatment effects are heterogeneous across time periods or across groups in staggered adoption designs. This bias is especially of concern if treatment effects differ between periods with many versus few treated groups, or between groups treated for many versus few periods.

In the case of the PNRU program, treatment effects on housing prices are likely to be highly heterogeneous across periods and neighborhoods for at least four reasons. First, with respect to heterogeneity across time periods, treatment effects might differ depending on period, especially because the 2008 housing crisis may have altered the impacts of the program in the following years. Then, with respect to heterogeneity across neighborhoods, the impact of renovation on housing prices is likely to depend on the tension on the urban unit's housing market. Given that our sample includes renovated neighborhoods located in 199 different urban units, this is likely to be a major source of heterogeneity. Furthermore, treatment effects may also depend on characteristics of the neighborhood itself, such as the share of public housing or the local level of criminality, or on characteristics of the renovation operations, such as the level of funding invested in the neighborhood or the share of demolitions. Finally, we can think that the most promising renovation projects were launched first, so that neighborhoods belonging to the first generations of renewal might have stronger treatment effects. This potential heterogeneity in treatment effects is combined with imbalance in treatment status in our data, as will be shown in Table 1.

Given these features, we use the alternative estimator proposed by DCDH. The $\mathrm{DID}_{M}$ estimator consists, in our case, in computing the average over the study period of difference-in-differences estimated for each year on neighborhoods where renovation started during this year (these neighborhoods are called "switchers") compared to neighborhoods not entering the treatment at the same date (i.e. non-renovated ZUS and renovated neighborhoods in which renovation has not started yet). This estimator can be used to compute instantaneous treatment effects (i.e. one period after the treatment starts) as well as time-varying treatment effects, $i$ periods after the treatment starts. In 
the latter case, the average evolution of housing prices between $T(n)-1$ and $T(n)+i$ in neighborhoods where renovation starts at time $T(n)$ is compared to that of neighborhoods that remain untreated at the same dates. As with the DFE estimator, we estimate the impact of the treatment $\{0,1\},\{2,3\},\{4,5\},\{6,7\},\{8,9\}$ and $\{10,11\}$ years after renovation started in the neighborhood and use the same control variables. ${ }^{17}$ The standard errors are computed using a block bootstrap at the neighborhood level.

The DID ${ }_{M}$ estimator relies on two assumptions. The first one requires that, in each period with switchers, at least one neighborhood keeps its treatment status. This happens in our setting because the sample includes never treated neighborhoods. The second hypothesis generalizes the common trend hypothesis of more traditional difference-in-differences estimations. It requires that the mean evolution of switching groups' outcomes would have been the same, in the absence of treatment, as that of control groups. In our case, this implies that, had renovation not been undertaken, housing prices in neighborhoods where renovation starts would have evolved in the same way as in non-renovated or in not-yet-renovated neighborhoods. The test of this hypothesis is based on the estimation of placebo effects for housing prices' evolutions between two consecutive periods before the start of the treatment. More specifically, the placebo effect $-i$ for groups entering the treatment at time $T(n)$ is based on the evolution of housing prices between $T(n)-i-1$ and $T(n)-i$.

The DID ${ }_{M}$ estimator is demanding in terms of data, as the estimate of the $+i$ temporal effect is based on neighborhoods in which transactions occurred at time $T(n)-1, T(n)$ and $T(n)+i{ }^{18}$ By way of comparison, the classical DFE estimator only requires each neighborhood to have transactions at two distinct dates at least, whatever the date. Moreover, the $\mathrm{DID}_{M}$ estimator is valid for controls at the neighborhood $\times$ period level and is therefore estimated here on data aggregated at this level. These two features of the DID $_{M}$ estimator yield larger standard errors than with the more classical DFE estimator. This is why we also show results based on DFE regressions.

\section{Data}

\subsection{Data sources}

Our analysis exploits a dataset derived from notaries registration of housing transactions and covering metropolitan France between 2000 and 2014 in even years. ${ }^{19}$ The data comprise the date and

\footnotetext{
${ }^{17}$ The DID $M$ estimator is implemented using the did_multiplegt Stata package. Because the trend option of this package only allows linear or non parametric trends, and the latter would consume too many degrees of freedom given the number of urban units in the sample, we include linear urban unit trends and not quadratic ones as with the DFE estimator. The placebo coefficients show that this change in the form of urban unit trends still allows to verify the extended parallel trends assumption.

${ }^{18}$ Observations at $T(n)-1$ and $T(n)$ are required to define the change in the treatment status of the neighborhood. As noted by DCDH, the properties of the DID $_{M}$ estimator hold even if some groups appear or disappear over time. As to placebo effects, they require a neighborhood to be observed in the data at four different periods, namely at time $T(n)-1$ and $T(n)$, and at $T(n)-i-1$ and $T(n)-i$ for placebo effect $-i$.

${ }^{19}$ The French Ministry for an Ecological and Inclusive Transition that gave us access to this data only purchased
} 
price of transaction, the geographical coordinates of the housing unit transacted, some of its characteristics (among which apartment or house, number of rooms, number of bathrooms, floorspace, construction period and plot land area for houses) and some characteristics of the buyer and seller (occupation, marital status, municipality of residence, sex, nationality, year of birth). Given our empirical strategy, we only retain from this dataset transactions located in an urban policy neighborhood. We apply to this dataset the same treatments as those employed by the French National Institute for Statistics (INSEE) to produce housing prices indices at the local level (Indice Notaires$I N S E E)$. First, we suppress atypical housing units. ${ }^{20}$ Second, we keep only private sales of housing units free of occupation, exclusively dedicated to housing and acquired in full ownership. Third, we suppress housing units with non-standard dimensions or price. ${ }^{21}$ Eventually, in order to deal with some records of bad quality in terms of match between characteristics of the housing unit and transaction price, we run the baseline regression corresponding to Equation (1) and set aside the 5\% of transactions for which the gap between predicted and observed price is the largest. After these treatments, the database contains about 72,000 transactions located in 647 neighborhoods.

We merge this data with information on PNRU operations in the 572 renovated neighborhoods located in metropolitan France. This information, provided by the National Agency for Urban Renewal (ANRU), includes the amounts allocated by the Agency to each neighborhood, the amounts provided by other financing partners, such as social landlords or municipalities, the number of housing units demolished, constructed and renovated, and the dates at which the Agency supplied funds in each neighborhood. Finally, we complete the data with local-level socio-economic and income characteristics from the 1999 French Census (Recensement de la Population 1999) and localized fiscal revenues data (Revenus Fiscaux Localisés 2001) provided by the French Institute of Statistics (INSEE).

These different data sources are not all at the same geographical scale. While housing transactions are located according to their geographical coordinates, information on investments made for renewal operations are available at the level of urban policy neighborhoods while Census and revenue data are available at the IRIS level (an infra-communal geographical unit defined for statistical purposes and corresponding to around 1,800 to 5,000 inhabitants). With the help of a geographical information system, we find the urban policy neighborhood corresponding to each transaction and define treatment indicators at the transaction level. Then, as urban policy neighborhood borders do

\footnotetext{
even years from the French Notaries Association.

${ }^{20}$ i.e. for apartments: artist's workshop, maid room, attic awaiting conversion, caretaker's dwelling, loft, villa, high standing; and for houses: chalet, tower, windmill, old train station, farm, large property, castle, private mansion, host house, villa.

${ }^{21}$ i.e. we keep, for apartments: units with less than or 9 rooms, a floor space comprised between 10 and 200 square meters, a price between $€ 1,500$ and $€ 5,000,000$, a square meter price of less than $€ 25,000$; for houses: units with less than or 13 rooms, more than 20 square meters and less than 300 square meters, more than 9 square meters lot size, a price of more than $€ 1,500$, and, if the house is located outside the Parisian urban area, the house must have a price lower than $€ 15,000,000$.
} 
not match IRIS borders, the former comprising several IRIS or parts of IRIS, we use the intersection rates between IRIS and neighborhoods to estimate the socio-economic characteristics at the urban policy neighborhood level and report this information for each transaction.

\subsection{Descriptive statistics}

The distribution of transactions in the renovated and non-renovated neighborhoods is displayed in Table 1. It can be noted that the treatment group is larger than the control group, both in terms of number of neighborhoods and of transactions, with 415 renovated neighborhoods and 232 nonrenovated ones. In addition, the number of renovated neighborhoods represented in our sample, 415, is lower than the 572 selected in the program in metropolitan France. This difference is due to the fact that, in a sizable number of renovated neighborhoods, no transaction took place at the dates under study, because these neighborhoods are small and largely constituted of public housing units. There are on average 111.6 transactions (s.d. 204.3) per neighborhood for the 14-years period observed in our dataset. ${ }^{22}$ When comparing renovated and non-renovated neighborhoods, the number of transactions over the period is higher in renovated neighborhoods by about 34 transactions.

Focusing on transactions located in renovated neighborhoods, Table 1 also shows the distribution of the year of first funding obtained from the renewal agency (ANRU). In most renewed neighborhoods (230 out of the 415 renovated neighborhoods in our sample), ANRU signed its first financial commitment as early as 2004. In a sizable number of neighborhoods (122), the first funding was obtained between 2005 and 2007. Only in 63 neighborhoods did renovation start between 2008 and 2014. The distribution of treatment adoption over time and across neighborhoods is hence highly non-uniform, especially as there are neighborhoods treated for the most part of the observation period and others treated only at the end of the period.

Table 2 presents some descriptive statistics of the housing transactions data. It shows that the mean transaction price is lower in renovated than in non-renovated neighborhoods, with $€ 105,000$ per transaction in renovated neighborhoods versus $€ 136,000$ in the others. The floor space, the share of houses and the share of blue-collar and white-collar workers among housing sellers and buyers are also greater in renovated neighborhoods. Yet, the proportions of inhabitants who are French citizens, blue-collars or executives are quite similar, as well as the share of intermediate category housing buyers and sellers.

Figure 1 shows the evolution of average housing prices in renovated and non-renovated neighborhoods (1) in the Parisian urban unit, (2) in Lyon, Marseille and Lille pooled together, and (3) in all

\footnotetext{
${ }^{22}$ We remind that only even years are observed
} 
Table 1: Number of neighborhoods and transactions, by type of urban policy neighborhood and starting date of renewal operations

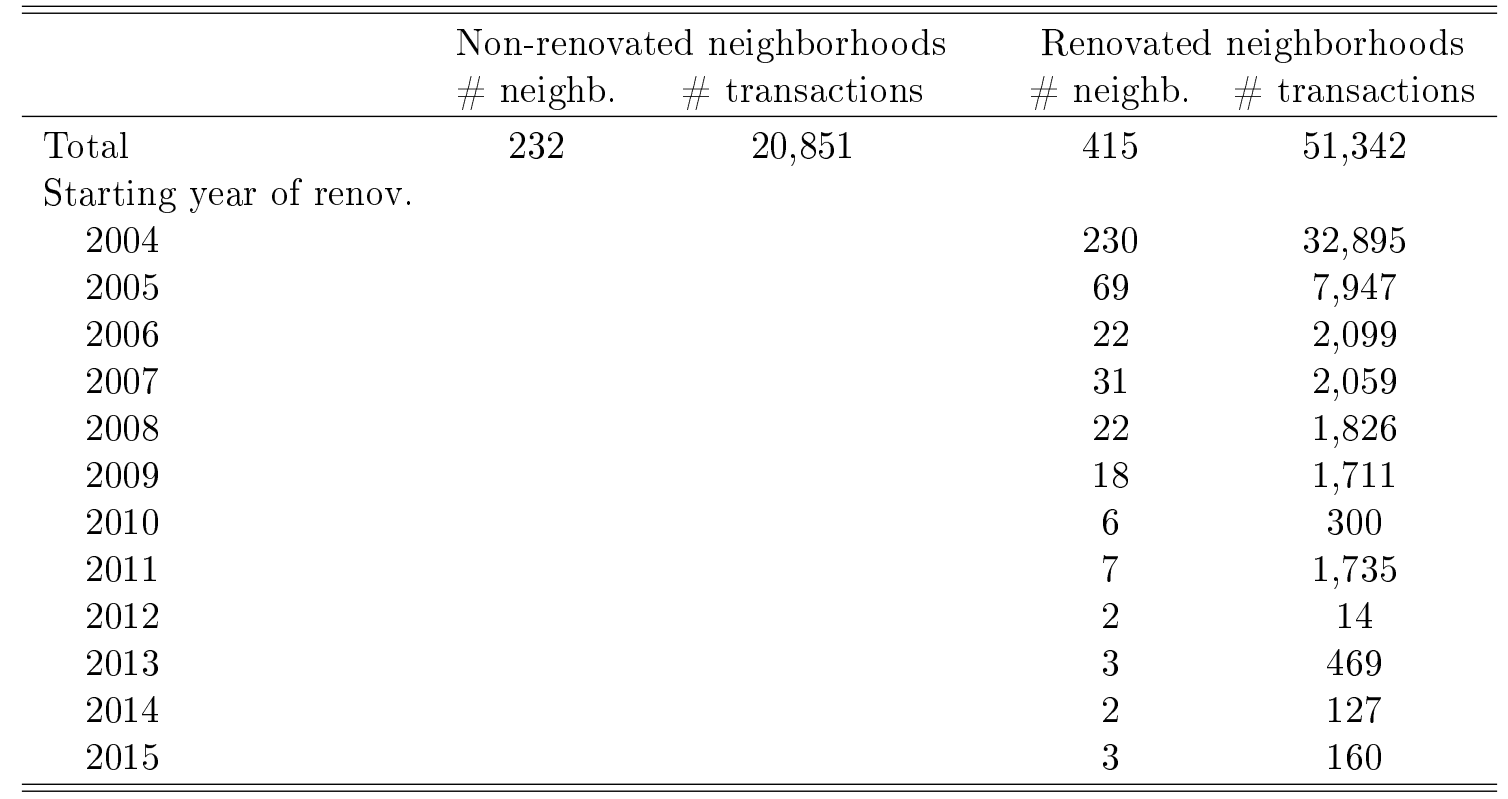

the other urban units in our sample. Although standard deviations are very large, we can observe that prices exhibit similar patterns of evolution in each of the three sub-samples. Prices in nonrenovated neighborhoods are generally higher and the gap with renovated neighborhoods appears to increase over time. Figure 2 complements this figure by decomposing the sample of transactions depending on the starting year of renovation in the neighborhood. It shows that whatever the starting year, the evolution of prices before renovation is similar to that of non-renovated areas. Figure A3 in Appendix is the counterpart of Figure 1 for the volume of transactions per neighborhood. Here also, there are no significant differences between neighborhoods in the treatment group and other neighborhoods. Eventually, the same type of graph is drawn in Figure A4 for the shares of housing buyers and sellers in the three socio-professional categories under study. These graphs show that these shares followed close to parallel trends in renovated and non-renovated neighborhoods before most renovation projects started. After the start of renovation, the shares of executive buyers and executive sellers seem to have decreased in renovated neighborhoods relatively to non-renovated ones, while the gap between the shares of intermediate category buyers in treated and non-treated areas seems to have progressively disappeared, although the large standard deviations do not allow to draw any conclusion. 
Table 2: Descriptive statistics on transactions. Renovated and non-renovated neighborhoods

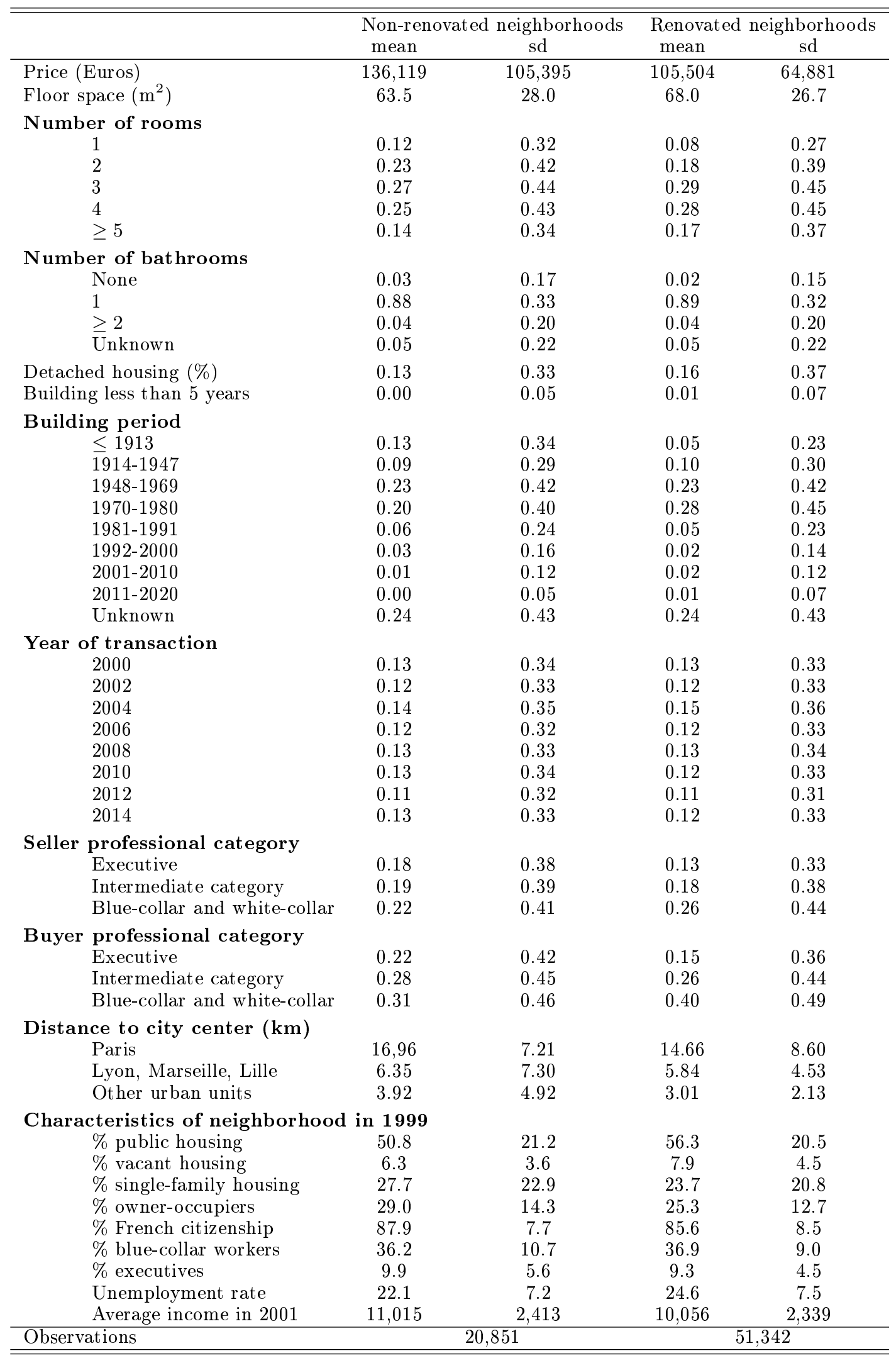



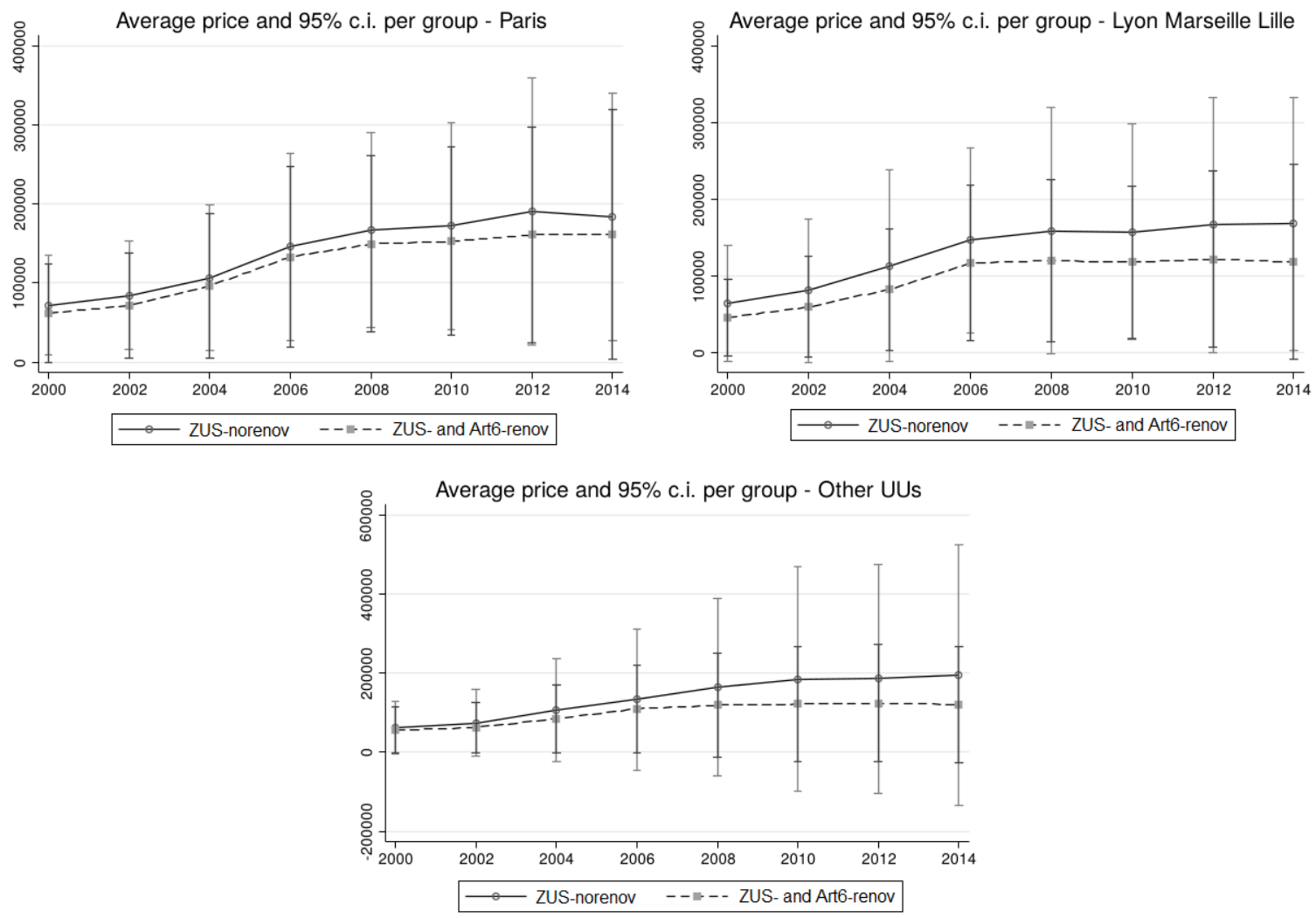

Figure 1: Evolution of average housing prices in renovated and non renovated urban policy neighborhoods in the Parisian urban unit (top left graph), Lyon, Marseille and Lille urban units (top right graph), in the other urban units (bottom graph)

\section{Results}

In this section, we first discuss the respective advantages of our two estimators. We then present the results, starting with the global impact of the program on housing prices over the whole period following the first renovation operation and the time-varying treatment impacts. After that, we test the common trend hypothesis, explore the potential for heterogeneous impacts and present some robustness checks. Finally, we evaluate the effects of the program on two complementary outcomes: transaction volumes and socio-professional categories of buyers and sellers.

\subsection{Relative advantages of the DFE and DID $_{M}$ estimators}

To start with, we apply the two steps suggested by DCDH in order to evaluate the potentiality of bias in the DFE estimate. We first compute the weights implied in the decomposition of the DFE estimator as an average of neighborhood-level treatment effects. ${ }^{23}$ We find that $27.1 \%$ of these weights are negative and that they are significantly correlated with the year of the transaction

\footnotetext{
${ }^{23}$ The following results are obtained with the twowayfeweights Stata package.
} 


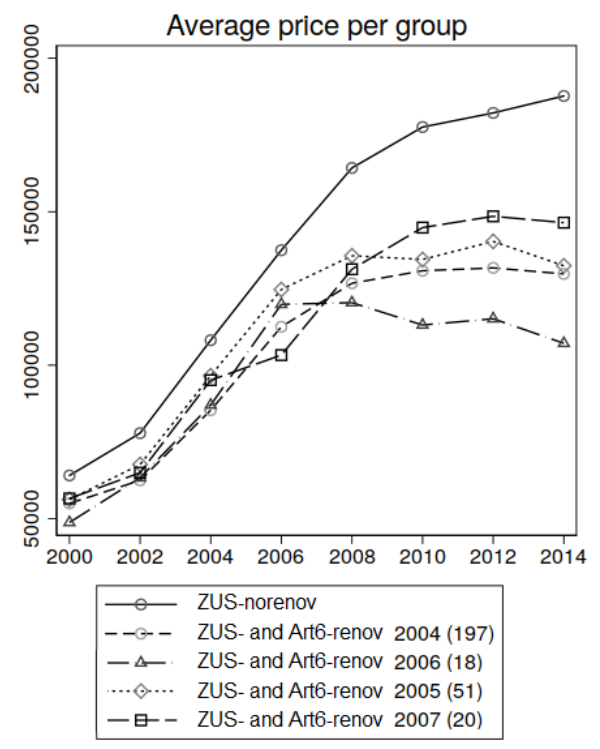

Figure 2: Evolution of average housing prices in renovated and non renovated urban policy neighborhoods, depending on the starting date of renovation. Number of neighborhoods in parentheses. Neighborhoods where renovation started after 2007 are not shown for the sake of readability.

(with a correlation coefficient of 0.468 ) and with the starting year of renovation (with a correlation coefficient of -0.375). Given that the individual treatment effects are likely to depend on these two dimensions for reasons explained before, the estimation of the average treatment effect based on the DFE estimator might be biased. We then compute the ratio of the absolute value of the DFE estimate $\left(\left|\hat{\beta}_{T}\right|\right.$ in Equation (1)) over the standard deviation of weights, which is an indicator of the amount of treatment effect heterogeneity that would lead to a DFE estimate with a sign opposite to that of all individual treatment effects. The value of this ratio is 7.1 , which suggests that only a large amount of treatment effect heterogeneity would lead to a DFE estimate of opposite sign as compared to the real impact of the program. Although this observation tends to be reassuring with respect to the quality of the DFE estimate, such a large heterogeneity in treatment effects can not be totally excluded. The results regarding the reliability of the DFE estimate are thus ambiguous and advocates in favor of $\operatorname{DID}_{M}$ estimations, of which unbiasedness is ascertained.

On the other hand, the DFE estimator can be combined with matching and weighting procedures in order to improve the comparability of treated and control groups, which is not possible with the DID $_{M}$ estimator. Additionally, the DFE estimator has the advantage of yielding more precise estimates than the $\mathrm{DID}_{M}$ estimator. Indeed, several specificities of the $\mathrm{DID}_{M}$ estimator increase the size of standard errors. First, the $\operatorname{DID}_{M}$ method uses data aggregated at the level of neighborhood $\times$ pair of years. Second, it uses fewer neighborhoods than the DFE method, because the requirement for a neighborhood to be taken into account in the estimation is more stringent, as explained in 
Section 3. Eventually, as noted by DCDH, in the very stylized case where errors can be assumed to be homoskedastic and uncorrelated, the Gauss-Markov theorem implies that the DFE estimator is the lowest variance estimator. All these factors are likely to explain the larger standard deviation of the $\operatorname{DID}_{M}$ estimates that will be observed in the results in the next paragraphs. The bias-variance trade-off between the DID $_{M}$ and the DFE estimators conjectured by DCDH is hence verified in our setting, with the $\mathrm{DID}_{M}$ estimator allowing for the alleviation of bias and the DFE estimator for the reduction of variance.

Given the mitigated results regarding the DFE estimate's bias and its merit in terms of variance, we present in the following results based on both DFE and DID $_{M}$ estimators.

\subsection{Urban renewal policy impact on property prices}

Global treatment effects. We start by analyzing the global effect of the program on housing prices at the aggregate level of France, estimating Equation (1) for the DFE estimation and then its DID $_{M}$ counterpart. These results are presented in Table 3, where explanatory variables are progressively introduced. In Column 1, only neighborhood and year fixed effects are included in the regression. In Column 2, housing controls are added. In Column 3, the distance of the transaction to the center of the urban unit is further introduced. Eventually, in Column 4, urban unit trends complete the set of control variables. ${ }^{24}$ Table 3 indicates that the estimated effect of the PNRU program on housing prices tends to zero with the introduction of additional control variables. Indeed, the estimated effect varies, in the case of the $\operatorname{DID}_{M}$ method, from a non-significant effect of around $6.5 \%$ in Column 1 to a non-significant effect of around $0.3 \%$ in our preferred specification in Column 4 . In the case of the DFE method, the estimated effect varies from a non-significant $-5.9 \%$ in Column 1 to a non-significant effect of around $1.1 \%$ in Column 4 . Introducing housing characteristics especially mitigates the estimated $\mathrm{DID}_{M}$ coefficient and, to a lesser extent, the DFE coefficient, which suggests that housing units transacted in neighborhoods under renovation probably experienced a decrease in quality relatively to housing units transacted in control neighborhoods. When all explanatory variables are included, the estimate of global treatment effects given by the DFE estimator (1.1\%) is compatible to that obtained with the $\operatorname{DID}_{M}$ estimator (0.3\%), given the size of the standard errors.

On the overall, Table 3 suggests that the program did not have a significant impact on housing prices, or that this effect was smaller than $3.5 \%$ (resp. $2.9 \%$ ) on average according to the upper bound of the confidence interval of the $\operatorname{DID}_{M}$ (resp. DFE) coefficient in Column 4.

\footnotetext{
${ }^{24}$ Table A1 in Appendix gives the estimated coefficients for the control variables in the four DFE estimations. Most control variables are very significant and their estimated effects on housing prices are consistent across specifications and in line with common sense. In particular, estimated year fixed effects suggest that housing prices increased from 2000 to 2008 , but decreased afterwards on average, which is consistent with the timing of the 2008 crisis.
} 
Table 3: Impact of the PNRU program on housing prices - Different sets of controls

\begin{tabular}{|c|c|c|c|c|}
\hline & $\begin{array}{c}\text { Fixed effects } \\
\text { (1) }\end{array}$ & $\begin{array}{c}+ \text { Housing controls } \\
(2)\end{array}$ & $\begin{array}{c}+ \text { Distance } \\
(3)\end{array}$ & $\begin{array}{c}+ \text { Urb. unit trends } \\
(4)\end{array}$ \\
\hline \multicolumn{5}{|l|}{ DID $_{M}$ estimator } \\
\hline$\beta_{T}^{(a)}$ & $\begin{array}{l}-0.0646 \\
(0.0503)\end{array}$ & $\begin{array}{l}-0.0044 \\
(0.0213)\end{array}$ & $\begin{array}{l}-0.0027 \\
(0.0213)\end{array}$ & $\begin{array}{c}0.0030 \\
(0.0162)\end{array}$ \\
\hline Total observations $^{(b)}$ & \multicolumn{4}{|c|}{100,693} \\
\hline Total switchers $^{(c)}$ & \multicolumn{4}{|c|}{38,600} \\
\hline \multicolumn{5}{|l|}{ DFE estimator } \\
\hline$\beta_{T}(a)$ & $\begin{array}{c}-0.0594 \\
(0.0356)\end{array}$ & $\begin{array}{c}-0.0352 \\
(0.0226)\end{array}$ & $\begin{array}{l}-0.0348 \\
(0.0227)\end{array}$ & $\begin{array}{c}0.0105 \\
(0.0096)\end{array}$ \\
\hline R-squared & 0.513 & 0.824 & 0.824 & 0.847 \\
\hline Observations & \multicolumn{4}{|c|}{72,193} \\
\hline \multicolumn{5}{|l|}{ Controls } \\
\hline Years and neigh. fixed effects & $\mathrm{X}$ & $\mathrm{X}$ & $\mathrm{X}$ & $\mathrm{X}$ \\
\hline Housing unit characteristics & & $\mathrm{X}$ & $\mathrm{X}$ & $\mathrm{X}$ \\
\hline Distance to urb. unit center & & & $\mathrm{X}$ & $\mathrm{X}$ \\
\hline Urban unit time trends & & & & $\mathrm{X}$ \\
\hline
\end{tabular}

Notes: The dependent variable is the $\log$ price of the housing transaction. Estimation method is OLS. (a) $\beta_{T}$ is the estimated average effect of renovation computed over the years following the start of renovation. For the DFE method, it corresponds to $\beta_{T}$ in Equation (1). For the DID $M$ method, it is computed as a weighted average of time-varying effects, with weights proportional to number of switchers used in each time-varying effect estimation (prop_number_switchers option in the did_multiplegt Stata package) (b) The total number of observations is the sum over time of the numbers of transactions used to estimate each effect. (c) The total number of switchers is the sum over time of the numbers of transactions in neighborhoods entering the treatment. Housing unit characteristics are described in the data section. Urban unit time trends are quadratic for the DFE estimator and linear for the $\mathrm{DID}_{M}$ estimator. A trend specific to the municipality of Paris is included. Robust standard errors clustered at the neighborhood level in parentheses. ${ }^{* * *} \mathrm{p}<0.01,{ }^{* *} \mathrm{p}<0.05,{ }^{*} \mathrm{p}<0.1$.

Time-varying treatment effects. Figure 3 displays the time-varying effects of the program based on DID $_{M}$ and DFE estimates, with the same control variables as in Column 4 of Table 3. This temporal decomposition of effects increases confidence intervals in both methods, due to a decrease in the number of observations available for the computation of each estimate. Nevertheless, the graphs seem to corroborate the results of Table 3. Indeed, non-negligible point estimates are obtained after 4-5 and 6-7 years in the DFE method, but they are not significant at the $5 \%$ level and point estimates go down to 0 after 8-9 and 10 years. The DID $_{M}$ method, based on a more robust but less precise identification strategy, exhibits a similar pattern with, nonetheless, one significant effect after 4-5 years. Overall, the time-varying estimates thus confirm the absence of a significant or sustained impact of the program on housing prices.

Placebos and pre-trends. Both identification methods used in this paper are based on the hypothesis that the evolution of housing prices is the same in the treated and control neighborhoods before the start of renovation. Figure 3 presents, for the DID $_{M}$ method (left panel), the placebo 

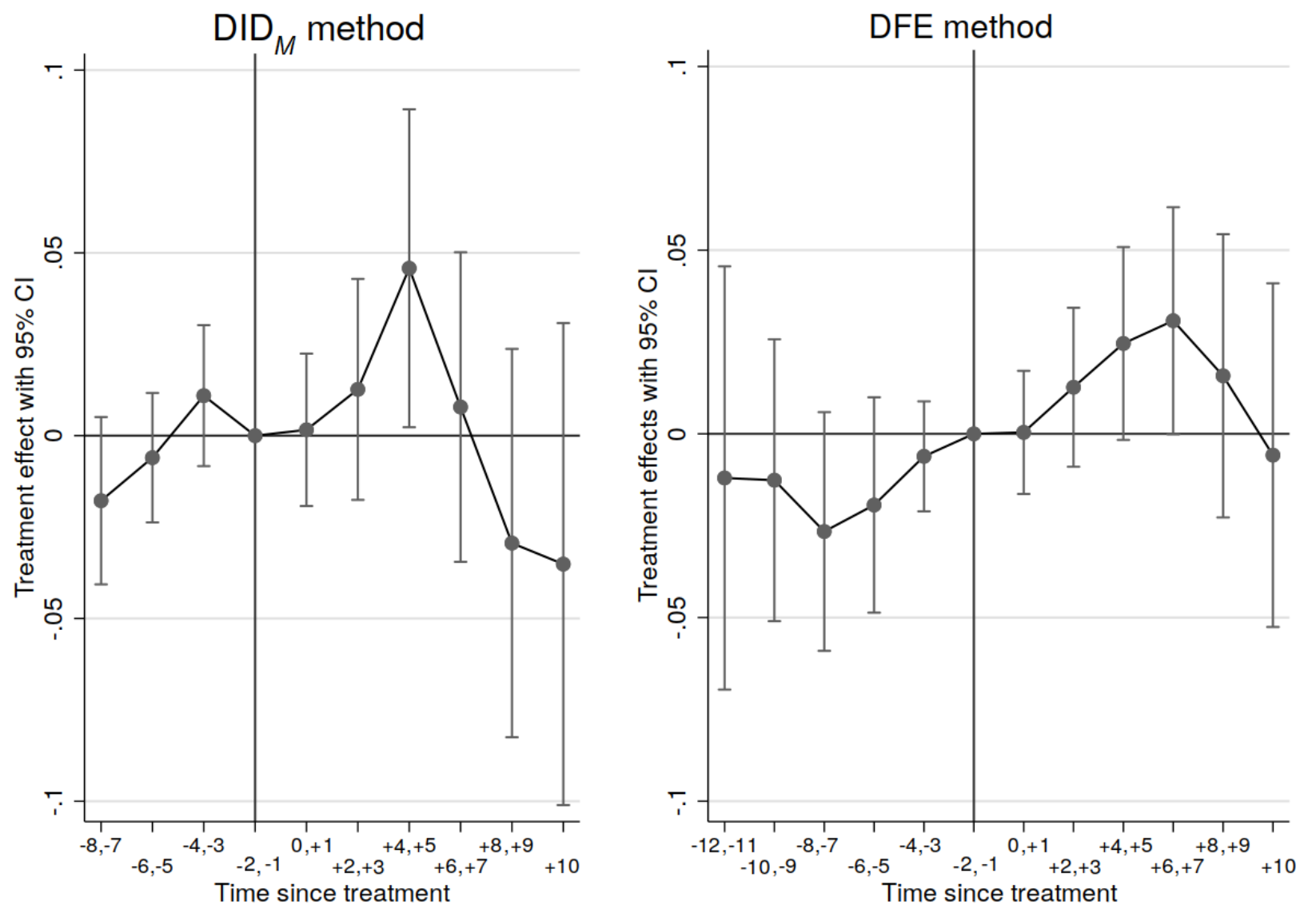

Figure 3: Estimated time-varying impacts of the PNRU program on housing prices, and placebo or pre-trend coefficients 
effects, and, for the DFE method (right panel), the pre-trend coefficients. ${ }^{25,26}$ It is clear that all pre-trend and placebo coefficients are small and not significantly different from 0 , which suggests that treated and control groups indeed experienced similar housing price trends before the start of renovation.

Heterogeneities. Taking advantage of the unusually large scale of this urban renewal program, we examine in this subsection whether the non-significant global impact of the program hides some heterogeneous effects that may countervail each other. We focus on three different heterogeneity dimensions: the size of the urban unit the neighborhood is located in, the amount of funding per housing unit received by the neighborhood for its renovation, and the initial share of public housing in the neighborhood. ${ }^{27}$ The size of urban unit is likely to be correlated to tension on the housing market, hence a source of treatment effect heterogeneity. The other two dimensions are likely to be linked to treatment intensity, therefore also a potential source of differenciation in our sample.

First, we divide the sample into two categories of transactions, those located in the four most populous urban units of France (i.e the four with more than one million inhabitants: Paris, Lyon, Marseille and Lille), and those located in the rest of metropolitan France. In Table 4, Column 1 shows the mean impact of the program in the four largest urban units, and Column 2 the mean impact of the program in the rest of France. These two impacts are not significantly different from zero, irrespective of the method. Their standard errors also indicate that they are not statistically different from each other.

Then, we investigate whether the amount of funding per housing unit received by the neighborhood for its renovation modifies the impact of the program. To this aim, we divide the sample of treated transactions into two categories, those located in neighborhoods that received more than the median funding per housing unit, i.e. more than $€ 24,268$ per housing unit, and those located in

\footnotetext{
${ }^{25}$ For an easier comparison with DFE results, the graphs presented here for DID $M$ placebos tests differ from those produced by the did_multiplegt Stata package, in two ways. First, the placebo coefficients plotted in our graphs represent evolutions during the $i$ periods preceding the start of renovation instead of one-year evolutions. Second, the $\mathrm{DID}_{M}$ placebo coefficients consider the evolution of the outcome between $T(n)-i-1$ and $T(n)-i$, so that a positive coefficient is associated with an increase in the outcome over time, whereas the opposite holds for DFE pre-trends, where a positive coefficients means that the outcome at time $-i$ is higher than at time 0 . We therefore take the opposite of placebo coefficients produced by the did_multiplegt Stata package. In practice, we compute the relevant sum of opposites of did_multiplegt placebo coefficients (i.e. for the $i$ periods preceding renovation for coefficient $-i$ ), weighted by the number of transactions associated with each estimated coefficient. The standard deviations are computed using the covariance matrix of estimated placebo coefficients. We also include in the graph a non-estimated 0 coefficient at time 0 , although the $\mathrm{DID}_{M}$ estimator does not involve any normalization. In summary, the $-i$ coefficient presented on the graphs refers to the difference $Y_{T(n)-i}-Y_{T(n)}$ with $Y$ the outcome and $T(n)$ the starting year of renovation. Although the two types of graphs are presented in parallel, we bear in mind that the two estimators are based on different identification methods and that the plotted coefficients have different interpretations.

${ }^{26}$ Whatever the estimator, we do not show coefficients estimated on 20 or less renovated neighborhoods. This is why there are only 6 coefficients for pre-trends and 3 coefficients for placebos. The difference between these two numbers is explained by the stronger data requirements of the DID $_{M}$ estimator, as exposed in subsection 3.2.

${ }^{27}$ The level of funding considered is the ratio of total funding over the number of housing units existing in 1999 as observed in Census data and not the number of housing units involved in the renovation. For the sake of simplicity, we only speak of "funding per housing unit" in the following.
} 
neighborhoods that received less than this median funding. ${ }^{28}$ In Table 4, Column 3 and Column 4 show that the mean impacts of the program estimated on the two subsamples are not statistically different from zero in both methods and they are clearly not statistically different from one another.

To finish with, we examine whether the initial share of public housing in the neighborhood affects the impact of the program. Indeed, the share of public housing could be an indicator of the treatment intensity, given that renovation operations are focused on public housing; it could also be that this share is an indicator of the initial level of deprivation, hence of potential for improvement. We divide the neighborhoods into two categories: above and below the median share of public housing in 1999 (i.e. $45.2 \%$ ). Column 5 and Column 6 show that the impacts estimated on the two subsamples are, once more, not significantly different from zero in the $\operatorname{DID}_{M}$ method. The effect of the program in neighborhoods with more than the median initial share of public housing, when estimated with the DFE method, is however significantly positive at the $5 \%$ level with a point estimate of $1.8 \%$. The point estimate with the $\operatorname{DID}_{M}$ method is very close (1.6\%), but statistically not significant. Still, the impacts measured in the two subsamples are clearly not statistically different from each other in both methods.

From this study of heterogeneities, it appears that the non-significant or hardly sizable effects of the program do hold on subsamples defined along the three investigated dimensions.

\subsection{Robustness checks}

In order to assess the robustness of these results, we first experiment alternative clustering levels and geographical fixed effects levels. We then use matching and weighting procedures combined with the DFE estimator to see whether improving the comparability between the treatment and control groups alters the results. Eventually, we verify that restricting our dataset to obtain a balanced panel of neighborhoods does not change the results for the time-varying effects.

Varying fixed effects and cluster levels. Table A2 shows estimates of the program's effect obtained with the DFE method, when varying both clustering and fixed effects levels. Column 1 repeats the baseline estimate shown in Column 4 of Table 3. In Column 2, the clustering is shifted to the urban unit level, and to the infra-communal IRIS level in Column 3. In Column 4, both fixed effects and clustering are set at the infra-communal IRIS level. ${ }^{29}$ It is clear from this table that

\footnotetext{
${ }^{28}$ The median funding per neighborhood in the ANRU data is $€ 55.4$ millions. The median funding per neighborhood in our sample of neighborhoods is higher with $€ 65.6$ millions, due to the selection of neighborhoods where transactions occured, which are likely to be larger. Moreover, the weight of large neighborhoods is increased in the transaction sample, which explains the higher median funding per neighborhood observed in our final data: $€ 109$ millions. This finally explains the rather high median funding per housing unit observed here. Our analysis therefore concerns higher than average funding levels, which gives even more weight to the result of absence of any impact of the program, if one assumes that higher funding should lead to higher impacts.

${ }^{29}$ We do not perform the same robustness check with the DID $_{M}$ estimator because it is valid only on data aggregated at the neighborhood $\times$ period level.
} 
Table 4: Heterogeneities in the program's impacts depending on urban unit size, amount of renovation funding and initial share of public housing

\begin{tabular}{|c|c|c|c|c|c|c|}
\hline & \multicolumn{2}{|c|}{ City size } & \multicolumn{2}{|c|}{ Funding level } & \multicolumn{2}{|c|}{ \% pub. housing in 1999} \\
\hline & $\begin{array}{c}\text { Four largest } \\
\text { (1) }\end{array}$ & $\begin{array}{l}\text { Others } \\
(2)\end{array}$ & $\begin{array}{l}\text { High } \\
(3)\end{array}$ & $\begin{array}{l}\text { Low } \\
(4)\end{array}$ & $\begin{array}{l}\text { High } \\
(5)\end{array}$ & $\begin{array}{l}\text { Low } \\
(6)\end{array}$ \\
\hline \multicolumn{7}{|l|}{ DID $_{M}$ estimator } \\
\hline$\beta_{T}$ & $\begin{array}{c}0.0302 \\
(0.0188)\end{array}$ & $\begin{array}{c}-0.0091 \\
(0.0274)\end{array}$ & $\begin{array}{c}0.0181 \\
(0.0176)\end{array}$ & $\begin{array}{l}-0.0092 \\
(0.0238)\end{array}$ & $\begin{array}{c}0.0159 \\
(0.0222)\end{array}$ & $\begin{array}{l}-0.0078 \\
(0.0343)\end{array}$ \\
\hline Observations $^{(a)}$ & 57,418 & 43,274 & 73,558 & 78,155 & 43,068 & 56,565 \\
\hline \multicolumn{7}{|l|}{ DFE estimator } \\
\hline$\beta_{T}$ & $\begin{array}{c}0.0096 \\
(0.0129)\end{array}$ & $\begin{array}{c}0.0118 \\
(0.0134)\end{array}$ & $\begin{array}{c}0.0113 \\
(0.0124)\end{array}$ & $\begin{array}{c}0.0218 \\
(0.0138)\end{array}$ & $\begin{array}{c}0.0181^{* *} \\
(0.0090)\end{array}$ & $\begin{array}{c}0.0159 \\
(0.0164)\end{array}$ \\
\hline R-squared & 0.856 & 0.814 & 0.860 & 0.850 & 0.846 & 0.851 \\
\hline Observations & 38,780 & 33,413 & 46,278 & 46,766 & 36,637 & 35,505 \\
\hline
\end{tabular}

Notes: Dependent variable is the log price of the housing transaction. Estimation method is OLS. $\beta_{T}$ is the estimated average effect of renovation over the years after renovation started. Column 1 corresponds to France's four largest urban units (Paris, Lyon, Marseille, Lille). Column 2 corresponds to the other urban units. Column 3 restricts the treated group to renovated neighborhoods that received more than $€ 24,268$ of funding per dwelling in the neighborhood. Column 4 restricts the treated group to renovated neighborhoods that received less than $€ 24,268$ of funding per dwelling in the neighborhood. Column 5 is for a subsample of neighborhoods with more than $45.2 \%$ public housing in 1999. Column 6 is for a subsample of neighborhoods with less than $45.2 \%$ public housing in 1999. Explanatory variables included are housing unit characteristics, distance, urban unit time trends and year and neighborhood fixed effects. Robust standard errors in parentheses are clustered at the neighborhood level. ${ }^{* * *} \mathrm{p}<0.01,{ }^{* *} \mathrm{p}<0.05,{ }^{*} \mathrm{p}<0.1$.

variations in the clustering and fixed effects geographical level do not drastically affect the results, the estimated impact of the program remaining insignificant in all of these alternative estimations. Nonetheless, clustering at the urban unit level shows a very slight positive impact of renovation on housing prices, significant at the $10 \%$ but not the $5 \%$ level.

Matching and weighting methods. In Table A3 in Appendix, we experiment alternative control groups with the DFE estimator, by using matching and weighting techniques in order to reduce the differences between the treated and control groups. We first estimate a propensity score corresponding to the probability for each transaction to be located in a renovated neighborhood. This score is estimated based on housing unit characteristics and neighborhood characteristics, the latter measured in relative value with respect to all deprived neighborhoods in the same urban unit and introduced with a quadratic form. ${ }^{30}$ Using this propensity score, a control observation corresponding to a weighted average of transactions located in a non-renovated neighborhood is built for each transaction located in a renovated neighborhood. ${ }^{31}$ In the first two columns of Table A3, we use a traditional kernel weighting. In the third and fourth columns, we use Lechner et al. (2011)'s procedure of weighted radius matching that consists in including in the control group of a

\footnotetext{
${ }^{30}$ The propensity score estimation results are presented in Table A4.

${ }^{31}$ Whatever the matching method, the region of common support is very large, in line with the idea that, although non-renovated and renovated neighborhoods slightly differ, they still have close profiles.
} 
treated transaction only transactions of which propensity score is within a given radius from that of the treated transaction, the radius being chosen depending on the density of control observations around each treated observation. In Column 1, the bandwidth chosen for the kernel matching is 0.001. In Column 2, it is 0.06. In Column 3, the maximum weight given to control transactions with respect to total weights is fixed to 0.1 and, in Column 4, to 0.025. After the implementation of these weighting procedures, we run the same difference-in-difference regression as previously. ${ }^{32}$

For Columns 5 to 7 of Table A3, we use another weighting technique, at the level of neighborhoods rather than transactions. ${ }^{33}$ More precisely, we estimate the probability for each urban policy neighborhood to be renovated, based on its characteristics. Then, we weight each neighborhood (renovated and non-renovated ones) depending on the difference between their estimated probability to be renovated and the observed proportion of renovated neighborhoods. ${ }^{34,35}$ The smaller this difference, the larger the weight associated to the neighborhood. We then run a DFE regression, using these weights. In Column 5, the optimal bandwidth is used (Silverman, 1986). In Column 6, the bandwidth is twice the optimal bandwidth. In Column 7 , the $25 \%$ of non-renovated neighborhoods that are the most distant from the threshold are suppressed while all the remaining neighborhoods are given a weight of 1 . It is clear from Table A3 that improving the comparability between the treated and control groups does not alter the results, as none of the estimated coefficients are significantly different from $0 .^{36}$

Using a balanced panel of neighborhoods. As a last robustness check, we restrict the panel of neighborhoods so as to obtain a balanced panel. Indeed, given the timing of renovation and the observation period in our data, the temporal effects of the program are not all estimated on the same sets of neighborhoods. For example, the impact of the program after 2 years is estimated on neighborhoods where renovation started in any year between 2004 and 2012, while the impact after 10 years is computed only on neighborhoods where renovation started in 2004. It is also the case for the estimation of pre-trends. This pattern leads to composition effects in the estimation of time-varying treatment effects. Consequently, as a last robustness check, we estimate again $\mathrm{DID}_{M}$ time-varying effects, keeping only neighborhoods in which renovation started in 2004 or 2005 and restricting the sample to time-varying effects comprised between $(-4,-3)$ and $(+8,+9)$, so that each

\footnotetext{
${ }^{32}$ The comparison of the treated and control groups before and after matching corresponding to Column 4 of Table A3 (Lechner's procedure with maximum weight 0.025) is presented in Table A5. Although numerous explanatory variables exhibit a substantial level of bias before matching, this bias becomes smaller than $10 \%$ for most of them after. The matching procedure can thus be considered to satisfactorily reduce the difference in characteristics between treated and control transactions.

${ }^{33}$ This technique is also used by Ahlfeldt et al. (2017).

${ }^{34}$ The following neighborhood-level weights are used: $w_{s}=\frac{1}{\lambda \sqrt{2 \pi}} \exp \left(-\frac{1}{2}\left(\frac{S_{S}-\bar{S}}{\lambda}\right)^{2}\right)$ with $\lambda$ the bandwidth.

${ }^{35}$ This procedure is, in spirit, close to a regression-discontinuity design, in a setting where there is however no explicit eligibility criteria.

${ }^{36}$ We also verified the absence of any pre-trend by estimating Equation (2).
} 
effect is estimated on exactly the same sample of neighborhoods. The results, depicted in Figure A5, suggest that the program may have had a limited and barely significant short term impact on housing prices, consistent with the effects depicted in Figure 3, but that this effect disappeared in the longer run. The corresponding effect averaged over the whole treatment period is non-significant. This last robustness check hence substantiates also our global result of an absence of effect of the PNRU program on housing prices at the aggregate level.

\subsection{Impacts of renovation on volumes of transactions and housing buyers and sellers social profile}

In this subsection, to obtain a broader picture of the effects of the PNRU program on housing markets in renovated neighborhoods, we complement the study of housing prices by an investigation of housing transaction volumes and buyers' and sellers' social profiles.

Volume of transacted housing units. To investigate the impacts of the program on the volume of housing transactions, we apply the same methodologies as for housing prices, considering the volume of transactions aggregated at the neighborhood $\times$ pair of years level. More precisely, the explained variable is the ratio between the number of housing transactions and the number of housing units in 1999, so that it represents the percentage of housing units that have been transacted in each observed year. For obvious reasons, only distance to the center and urban unit trends are included as control variables. The estimated impacts of the program on the volume of transactions based on DID $_{M}$ and DFE estimators are presented in Table 5, with the global impact in Column 1 and then impacts depending on city size, level of funding for renovation and initial share of public housing. We observe that the global estimated impact and the impacts depending on city size and level of funding are not significantly different from zero, irrespective of the estimator considered. However, neighborhoods with an initial share of public housing above the median have experienced a significant decrease in (private) housing transactions due to the renovation program. This decrease could translate a lower willingness to sell on the part of owners located in neighborhoods with more public housing because more substantial changes may be expected from the program in these neighborhoods, or reflect an increased uncertainty leading to fewer transactions. However, the difference in effects between neighborhoods with a high or a low share of public housing is clearly not significant at the 95\% level so that, taken together, Columns (6) and (7) only mildly suggest an heterogeneity in the program's effects depending on the initial share of public housing.

Sellers' and buyers' social profile. Beside prices of transacted housing units and their volume, our dataset also allows us to investigate a rarely available dimension of housing transactions, namely the socio-professional categories of housing sellers and buyers. To do so, we rely on the same $\mathrm{DID}_{M}$ 
Table 5: Impact of the PNRU on the ratio of number of housing transactions/number of housing units in 1999

\begin{tabular}{lccccccc}
\hline & Whole & \multicolumn{2}{c}{ City size } & \multicolumn{2}{c}{ Funding level } & \multicolumn{2}{c}{ Initial \% pub. housing } \\
& France & 4 largest & Others & High & Low & High & Low \\
& $(1)$ & $(2)$ & $(3)$ & $(4)$ & $(5)$ & $(6)$ & $(7)$ \\
\hline DID $M$ method & & & & & & & \\
$\beta_{T}$ & 0.000291 & 0.000704 & $3.15 \mathrm{e}-06$ & 0.000504 & $-4.97 \mathrm{e}-07$ & $-0.000927^{* * *}$ & 0.001498 \\
& $(0.000654)$ & $(0.001194)$ & $(0.000656)$ & $(0.000762)$ & $(0.000668)$ & $(0.000367)$ & $(0.001331)$ \\
Obs. & 5,183 & 1,858 & 3,325 & 4,242 & 4,010 & 3,123 & 1,945 \\
\hline DFE method & & & & & & & \\
$\beta_{T}$ & 0.000434 & 0.000139 & 0.000639 & 0.000590 & 0.000479 & $-0.000573^{*}$ & $0.000146^{*}$ \\
& $(0.000400)$ & $(0.000542)$ & $(0.000566)$ & $(0.000498)$ & $(0.000539)$ & $(0.000297)$ & $(0.000826)$ \\
Obs. & 4,249 & 1,434 & 2,815 & 3,273 & 2463 & 2,918 & 1,323 \\
R-squared & 0.881 & 0.776 & 0.906 & 0.887 & 0.783 & 0.703 & 0.905 \\
\hline
\end{tabular}

Notes: Transactions are counted at the level of urban policy neighborhoods. Dependent variable is the ratio of number of transactions in year $t$ over existing dwellings in 1999 in the urban policy neighborhood. Estimation method is OLS. $\beta_{T}$ is the estimated average effect of renovation over the years after renovation started. Column 1 is estimated on the whole sample. In Column 2, the sample is restricted to France's four largest urban units (Paris, Lyon, Marseille and Lille). In Column 3, the sample is restricted to the other urban units with at least one ZUS. Column 4 restricts the treated group to renovated neighborhoods that received more than the median level of funding. Column 5 restricts the treated group to renovated neighborhoods that received less than the median level of funding. Column 6 is for a subsample of neighborhoods with more than $45.2 \%$ public housing in 1999. Column 7 is for a subsample of neighborhoods with less than $45.2 \%$ public housing in 1999. Explanatory variables included are year, distance, urban unit trend, and neighborhood fixed effects. Robust standard errors clustered at the neighborhood level in parentheses. ${ }^{* * *} \mathrm{p}<0.01,{ }^{* *} \mathrm{p}<0.05,{ }^{*} \mathrm{p}<0.1$.

and DFE methods as described in Section 3. The variable of interest is a dummy indicating the socio-professional category of the seller or buyer. A linear probability model is estimated, with explanatory variables including urban unit time trends and distance to the city center only, as housing characteristics are likely to be endogenous with respect to the social category of sellers and buyers. In Table 6's Column 1, the variable of interest is a dummy equal to 1 if the seller belongs to the "executive" category and 0 if not. In Column 2, the variable of interest is the same, but for buyers. Columns 3 and 4 (resp. 5 and 6) are similar to Columns 1 and 2, for "intermediate" socioprofessional category (resp. "blue-collar" category). The estimates obtained for the whole sample are presented first (top panel), followed by estimates in the four largest urban units (middle panel) and in the other urban units (bottom panel).

Table 6 suggests that the PNRU program had indeed some impacts on the profiles of sellers and buyers, although these impacts' level of significance sometimes varies depending on the estimator. Note that the signs of the estimated effects nearly always coincide in the two methods (except in two cases with the "other cities" subsample) so that, when only the DFE estimate is significantly different from zero but the $\operatorname{DID}_{M}$ point estimate is close to it, one may think that the program led to a significant effect that cannot be captured with the DID $_{M}$ method because of its larger standard errors.

At the aggregate level of France, the only effect that is significant both in the $\operatorname{DID}_{M}$ and the DFE estimations concerns the share of intermediate category buyers, which appears to have increased 
due to the program (Table 6, column 4, top panel). Yet, this effect is only significant at the $10 \%$ (resp. 5\%) level in the $\operatorname{DID}_{M}$ (resp. DFE) estimation. When restricting the sample to the four largest urban units, this same effect becomes larger and more significant. The program is estimated to have increased the share of intermediate category buyers in the renovated neighborhoods of these cities by between $0.4 \%$ and $6.9 \%$ (resp. $1.1 \%$ and $4.8 \%$ ) according to the $95 \%$ confidence interval of the DID $_{M}$ (resp. DFE) estimate. However, the program does not appear to have had a similar effect in the other urban units.

Considering now the other estimates that are significantly different from zero in the DFE method at the aggregate level (but not in the DID $_{M}$ method), we can observe that the program appears to have reduced the share of executive buyers (at the $10 \%$ significance level) and increased the share of blue-collar sellers (at the $5 \%$ significance level). The corresponding point estimates obtained with the DID $_{M}$ method, though not significant, are greater than in the DFE method, which yields some support to both effects. Eventually, the DID $M$ method suggests that the share of executive sellers could have been reduced by the program (at a 10\% significance level). When looking at large versus smaller cities, it further appears that the share of sellers from the intermediate category decreased in the cities outside the four largest, while the share of blue-collars as sellers increased (although this result is only supported by the DFE estimate). This would mean that in the medium and small cities, intermediate categories tended to stay more in the renovated neighborhoods, contrary to lower-income categories.

In order to shed further light on those results, we investigate the time-vayring effects of the program on the transition probabilities of housing units from a given initial socio-professional category (the buyer's) to a given final socio-professional category (the seller's), focusing on the four largest cities, where the effects of the program are the strongest. To this aim, we use the DID $_{M}$ method and change the explained variable to a dummy equal to 1 if the transaction took place between a given initial socio-professional category and a given final one. Using this approach, we obtain nine graphs corresponding to the nine possible transitions between the executive, intermediate and blue-collar categories. We show in Figure 4 the three ones exhibiting the larger effects. First, the top-left graph shows that the program seems to have reduced the probability of transactions between executives. The bottom graph may suggest that the probability of transactions from an intermediate category seller to an executive buyer slightly increased, although none of the coefficients is significant at the $5 \%$ level. Eventually, the top-right graph indicates a clear increase in the probability of transactions from a blue-collar seller to an intermediate category buyer. These three effects are also obtained with the DFE method (see Figure A6 in Appendix).

Together, these results may be interpreted in the following way. The program led to a reduction in the share of executive buyers and sellers, to a reduction in the share of transactions between 
executives and, at the same time, to a slight increase in transactions between intermediate category sellers and executive buyers. Thus, the reduction in transactions between executives does not seem to translate in a reduction in the attractivity of renovated neighborhoods for executives, but rather an increased willingness of executives to stay in these neighborhoods and not sell their housing unit. This, in turn, encourages executives who cannot acquire a housing unit from their own socioprofessional category to increasingly buy from a lower socio-professional category (the intermediate category). Additionally, the share of buyers from the intermediate category and the share of bluecollar sellers increased, and the probability of an upward transition from a blue-collar seller to an intermediate category buyer increased. These effects corroborate each other, suggesting an increase in the attractivity of renovated neighborhoods and shifts of housing units in these neighborhoods from lower-income to higher-income categories. These upward transitions seem to correspond more to transitions from executives to medium-income households in the four largest cities, and to transitions from blue-collar to medium-income categories in small and medium cities.
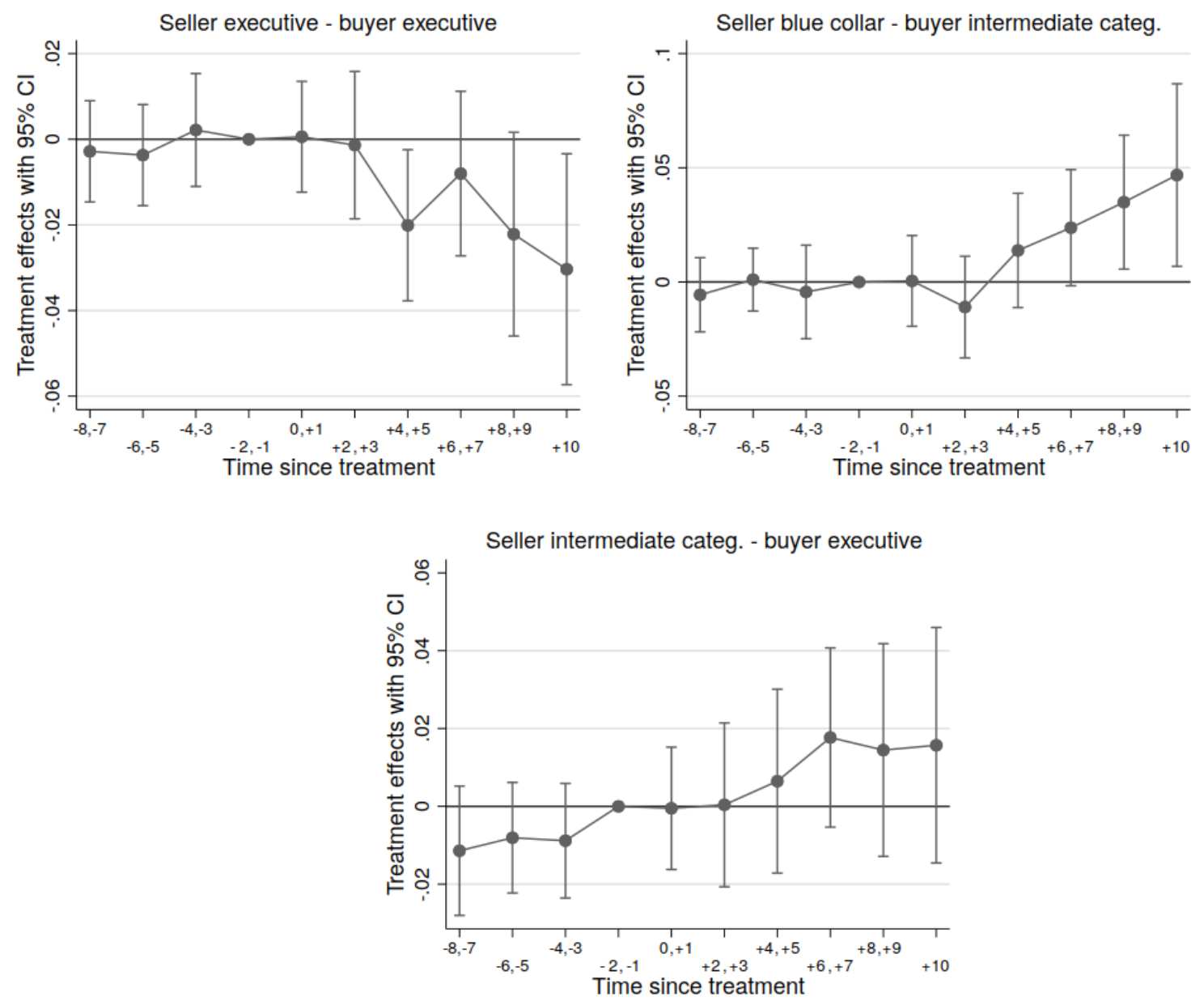

Figure 4: DID $M$ placebo and time-varying treatment effects on transitions probabilities in the four largest cities. Robust standard errors clustered at the neighborhood level 
Table 6: Impact of the PNRU on the socio-professional category of housing sellers and buyers

\begin{tabular}{|c|c|c|c|c|c|c|}
\hline & \multicolumn{2}{|c|}{ Executive } & \multicolumn{2}{|c|}{ Interm. cat. } & \multicolumn{2}{|c|}{ Blue-collar } \\
\hline & $\begin{array}{c}\text { sellers } \\
(1)\end{array}$ & $\begin{array}{c}\text { buyers } \\
(2)\end{array}$ & $\begin{array}{c}\text { sellers } \\
(3)\end{array}$ & $\begin{array}{c}\text { buyers } \\
(4)\end{array}$ & $\begin{array}{c}\text { sellers } \\
(5)\end{array}$ & $\begin{array}{c}\text { buyers } \\
(6)\end{array}$ \\
\hline \multicolumn{7}{|l|}{ Whole sample } \\
\hline \multirow[t]{2}{*}{ DID $_{M}$ estim. } & $-0.0169^{*}$ & -0.0131 & -0.0158 & $0.0224^{*}$ & 0.0193 & -0.0140 \\
\hline & $(0.0102)$ & $(0.0102)$ & $(0.0118)$ & $(0.0136)$ & $(0.0123)$ & $(0.0134)$ \\
\hline Total obs. & 100,009 & 100,009 & 100,009 & 100,009 & 100,009 & 100,009 \\
\hline \multirow[t]{2}{*}{ DFE estim. } & -0.00228 & $-0.0119^{*}$ & -0.0103 & $0.0180^{* *}$ & $0.0151^{* *}$ & -0.000570 \\
\hline & $(0.00606)$ & $(0.00609)$ & $(0.00719)$ & $(0.00704)$ & $(0.00741)$ & $(0.00734)$ \\
\hline Obs. & 61,904 & 65,678 & 61,904 & 65,678 & 61,904 & 65,678 \\
\hline \multicolumn{7}{|l|}{ Four largest cities } \\
\hline \multirow[t]{2}{*}{ DID $_{M}$ estim. } & $-0.0232^{*}$ & -0.0145 & 0.0080 & $0.0365^{* *}$ & 0.0232 & -0.0158 \\
\hline & $(0.0128)$ & $(0.0137)$ & $(0.0149)$ & $(0.0164)$ & $(0.0150)$ & $(0.0178)$ \\
\hline Total obs. & 57,284 & 57,356 & 57,284 & 57,356 & 57,284 & 57,356 \\
\hline \multirow[t]{2}{*}{ DFE estim. } & -0.0070 & -0.0133 & 0.00057 & $0.0295^{* * *}$ & 0.0062 & -0.0032 \\
\hline & $(0.0082)$ & $(0.0086)$ & $(0.00875)$ & $(0.0093)$ & $(0.0092)$ & $(0.0091)$ \\
\hline Obs. & 33,707 & 35,630 & 33,707 & 35,630 & 33,707 & 35,630 \\
\hline \multicolumn{7}{|l|}{ Other cities } \\
\hline \multirow[t]{2}{*}{ DID $_{M}$ estim. } & 0.00014 & 0.0027 & $-0.0420^{* *}$ & 0.0099 & 0.0050 & -0.0206 \\
\hline & $(0.01566)$ & $(0.0141)$ & $(0.0185)$ & $(0.0233)$ & $(0.0209)$ & $(0.0212)$ \\
\hline Total obs. & 42,724 & 42844 & 42,724 & 42844 & 42,724 & 42844 \\
\hline \multirow[t]{2}{*}{ DFE estim. } & 0.00538 & -0.00841 & $-0.0302^{* *}$ & 0.00113 & $0.0300^{* *}$ & 0.00237 \\
\hline & $(0.00816)$ & $(0.00790)$ & $(0.0124)$ & $(0.0106)$ & $(0.0121)$ & $(0.0124)$ \\
\hline Obs. & 28,197 & 30,048 & 28,197 & 30,048 & 28,197 & 30,048 \\
\hline
\end{tabular}

Notes: Dependent variable is a dummy equal to 1 if (1) the housing seller is an executive, (2) the housing buyer is an executive, (3) the housing seller belongs to an intermediate category, (4) the housing buyer belongs to an intermediate category, (5) the housing seller is a blue-collar, (6) the housing buyer is a blue-collar, and 0 if not. Estimation method is OLS. $\beta_{T}$ is the estimated average effect of renovation over the years after renovation started. Explanatory variables included are distance to the urban unit center and linear urban unit time trends for DID $M$ and quadratic urban unit time trends for DFE method. Robust standard errors clustered at the neighborhood level in parentheses. ${ }^{* *} \mathrm{p}<0.01,{ }^{* *} \mathrm{p}<0.05,{ }^{*} \mathrm{p}<0.1$.

\section{Conclusion}

In a context of urban segregation and concentration of poverty in deteriorating neighborhoods, urban renewal programs have been implemented in a number of countries, like France, Germany, Spain, the Netherlands and the US. A few attempts at measuring their impacts have been proposed in the literature, leading to contrasted results depending on the context and leaving open the question of efficiency of this type of intervention in changing the attractivity of these neighborhoods. Existing studies analyzed limited scale renovation programs or considered renovation's impacts at the city level. In this article, we analyze the effects of the French Programme National de Rénovation Urbaine, an ambitious urban renewal program led in around six hundreds of deprived neighborhoods and targeting large public housing developments and their environment. Using the $\mathrm{DID}_{M}$ estimator proposed by $\mathrm{DCDH}$ and complementing it by the potentially biased but also more precise traditional 
double fixed effect difference-in-differences estimator, we analyze the impact of this program on housing prices, volumes of transactions and buyers and sellers social profiles.

We do not find any significant impact of the French renovation program on local housing prices, even when studying separately neighborhoods that received a high amount of funding per housing unit, neighborhoods where the initial share of public housing was particularly large and neighborhoods located in the largest urban units of France where tension on the housing market is high. Our results indicate that the program had, in any case, an impact of less than $3.5 \%$ on housing prices. These results contrast with most studies on the impacts of urban renewal projects in the United States that find significant impacts of renovation on housing prices (Ding et al., 2000; RossiHansberg et al., 2010; Collins and Shester, 2013), but it is consistent with a number of studies led more recently in the U.S. (Chen et al., 2019) or in other contexts (Aarland et al., 2017; Ahlfeldt et al., 2017) that obtain small or insignificant effects of renovation. We do not find any significant impact of renovation on the volume of transactions either, apart from a decrease in neighborhoods likely to have experienced the most numerous demolitions. However, we do find sizable effects on the socio-professional characteristics of buyers and sellers. Indeed, we find evidence that the program led to an increased number of upward transitions of housing units (from a blue-collar seller to an intermediate category buyer or from an intermediate category seller to an executive buyer) and to a reduction of housing transactions among executives, suggesting an increased interest of upper socio-professional categories to invest in the renovated neighborhoods or to remain in them.

We interpret our results as evidence that, despite its non-significant effect on housing prices, the program was successful, in some measure, in driving renovated neighborhoods up on the social ladder. By looking at flows through the lens of housing units transactions instead of stocks of population, our analysis complements Guyon (2016) and González-Pampillón et al. (2019)'s studies of urban renewal impacts on poverty rates and population social composition. It allows indeed for a finer view on the social changes induced by urban renewal and exemplifies the fact that the absence of a sizable aggregate impact on housing prices may hide some non negligible effects on the social profile of new homeowners, that could be a signal of further changes in these neighborhoods.

The attraction of more intermediate category and executive buyers evidenced in our results may have all kinds of effects on the long-term trajectories of renovated neighborhoods, which are difficult to anticipate. One may expect positive impacts at school and on the labor market for members of poorer households, for example through network effects. However, it is difficult to predict whether these effects will be sizable. To finish with, in view of the amounts invested in the PNRU program and of the limited impacts estimated in the present article, our results appear to corroborate the idea that place-based policies may not be the most efficient mean to durably alter deprived neighborhoods' trajectories and to solve social ills. 


\section{$7 \quad$ References}

Aarland, K., Osland, L. and Guestland, A. (2017). Do area-based intervention programs affect house prices? A quasi-experimental approach. Journal of Housing Economics, 37, 67-83.

Ahlfeldt, G. M., Maennig, W. and Richter, F. J. (2017). Urban renewal after the Berlin Wall: A place-based policy evaluation. Journal of Economic Geography, 17 (1), 129-156.

Aliprantis, D. and Hartley, D. (2015). Blowing it up and knocking it down: The local and city-wide effects of demolishing high concentration public housing on crime. Journal of Urban Economics, 88, 67-81.

Alonso, J. M., Andrews, R. and Jorda, V. (2019). Do neighbourhood renewal programs reduce crime rates? evidence from england. Journal of Urban Economics, 110, 51-69.

Athey, S. and Imbens, G. W. (2018). Design-based analysis in difference-in-differences settings with staggered adoption. Tech. rep., National Bureau of Economic Research.

Barthélémy, F., Michelangeli, A. and Trannoy, A. (2007). La rénovation de la Goutte d'Or est-elle un succès? Economie 6 S Prévision, (4), 107-126.

Baum-Snow, N. and Marion, J. (2009). The effects of low income housing tax credit developments on neighborhoods. Journal of Public Economics, 93 (5-6), 654-666.

Borusyak, K. and Jaravel, X. (2017). Revisiting event study designs. Available at SSRN 2826228.

Chen, J., Glaeser, E. L. and Wessel, D. (2019). The (Non-)Effect of Opportunity Zones on Housing Prices. NBER Working Paper No. 26587.

Collins, W. J. and Shester, K. L. (2013). Slum clearance and urban renewal in the United States. American Economic Journal: Applied Economics, 5 (1), 239-273.

De Chaisemartin, C. and D'Haultfeullete, X. (forthcoming). Two-way fixed effects estimators with heterogeneous treatment effects. American Economic Review.

Ding, C., Simons, R. and BAKU, E. (2000). The effect of residential investment on nearby property values: evidence from Cleveland, Ohio. Journal of Real Estate Research, 19 (1), 23-48.

Eriksen, M. D. and Rosenthal, S. S. (2010). Crowd out effects of place-based subsidized rental housing: New evidence from the LIHTC program. Journal of Public Economics, 94 (11-12), 953-966.

Galster, G., Tatian, P. and Accordino, J. (2006). Targeting investments for neighborhood revitalization. Journal of the American Planning Association, 72 (4), 457-474.

González-Pampillón, N., Jofre-Monseny, J. and Viladecans-Marsal, E. (2019). Can urban renewal policies reverse neighborhood ethnic dynamics? Journal of Economic Geography, 20 (2), 419-457.

Goodman-Bacon, A. (2018). Difference-in-differences with variation in treatment timing. Tech. rep., National Bureau of Economic Research.

GuYon, N. (2016). Etude des effets de la rénovation urbaine sur l'évolution du bâti et du peuplement dans les quartiers ciblés entre 2004 et 2013. Tech. rep., Sciences Po et Université Nationale de Singapour.

- (2017). Is desegregation possible ? Evidence from social housing demolitions in France.

Koster, H. R. and Van Ommeren, J. (2019). Place-based policies and the housing market. Review of Economics and Statistics, 101 (3), 400-414.

Le Monde (2019). Ces villes au parc hlm devenu inutile. pp. June 1, 2019. 
Lechner, M., Miquel, R. and Wunsch, C. (2011). Long-run effects of public sector sponsored training in west germany. Journal of the European Economic Association, 9 (4), 742-784.

Neumark, D. and Simpson, H. (2015). Place-based policies. Handbook of Regional and Urban Economics, 5B, 1197-1287.

ONZUS (2013). Dix ans de programme national de rénovation urbaine: Bilan et perspectives.

Papke, L. E. (1993). What do we know about enterprise zones? Tax Policy and the Economy. Tech. rep., National Bureau of Economic Research.

Rossi-Hansberg, E., Sarte, P.-D. and Owens III, R. (2010). Housing externalities. Journal of Political Economy, 118 (3).

Silverman, B. W. (1986). Density estimation for statistics and data analysis. In Monographs on Statistics and Applied Probability. CRC Press.

Van Beckhoven, E. and Van Kempen, R. (2003). Social effects of urban restructuring: a case study in Amsterdam and Utrecht, the Netherlands. Housing studies, 18 (6), 853-875. 


\section{Appendix}
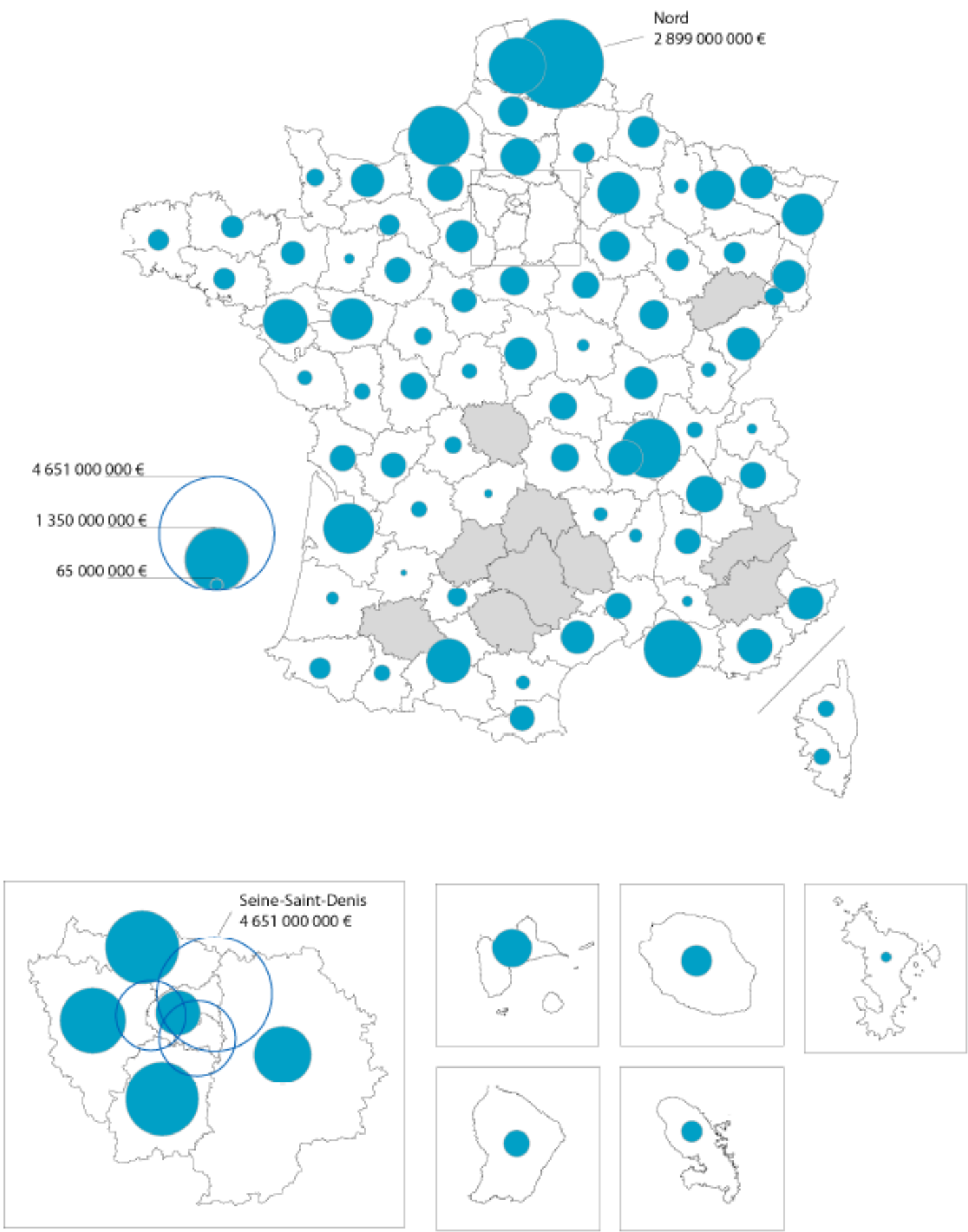

Source : fichiers de programmation Agora au 31 décembre 2012.

Figure A1: Geographical distribution of PNRU funding at the departmental level 


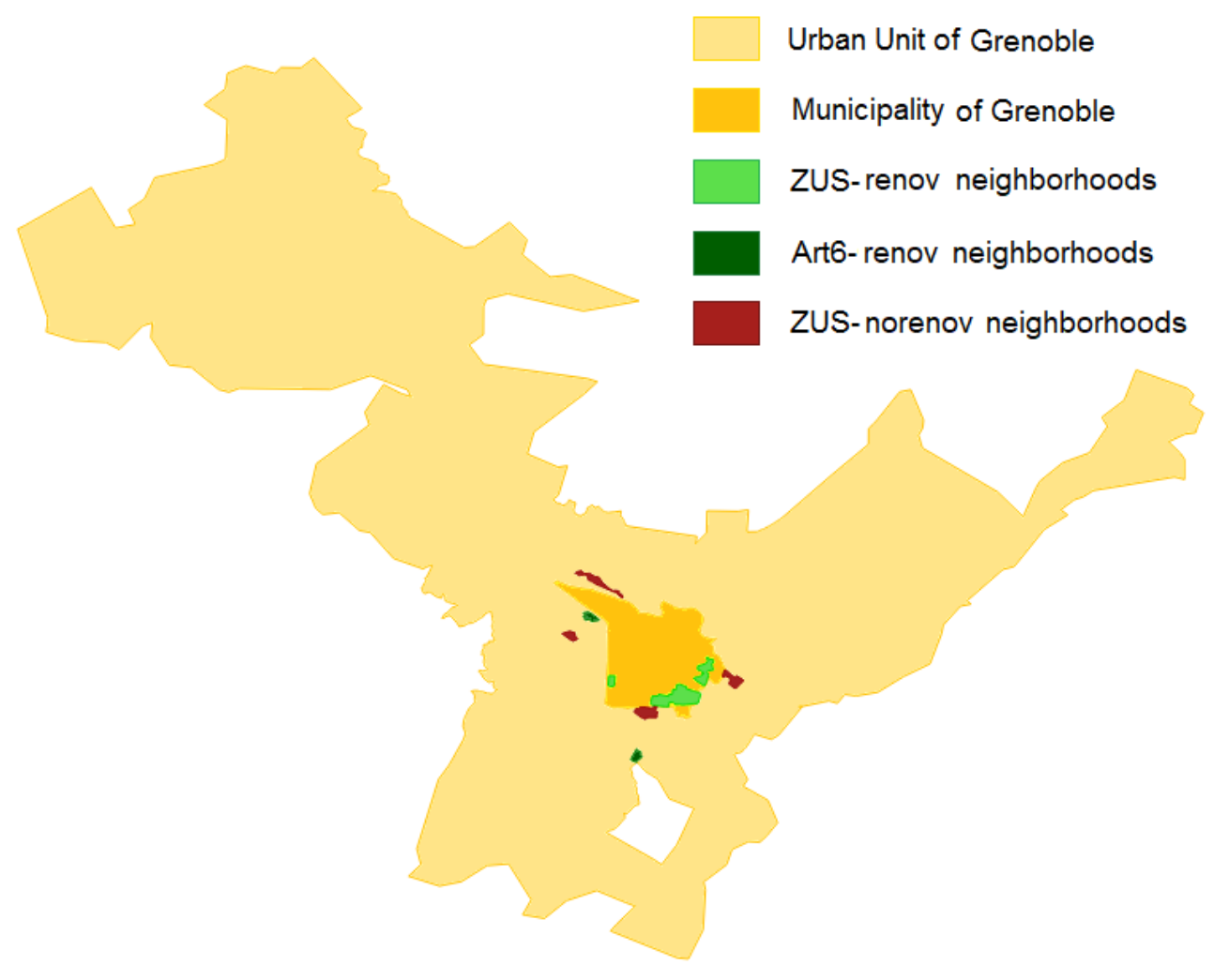

Figure A2: The urban unit of the city of Grenoble and its urban policy neighborhoods

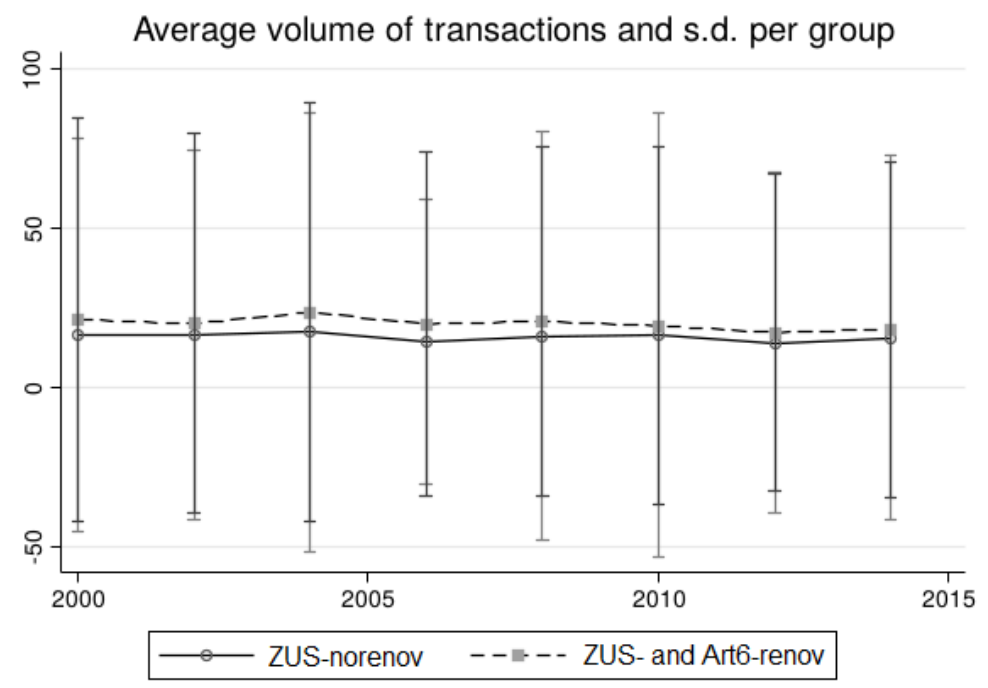

Figure A3: Evolution of the average number of transactions per neighborhood in renovated and non renovated urban policy neighborhoods 

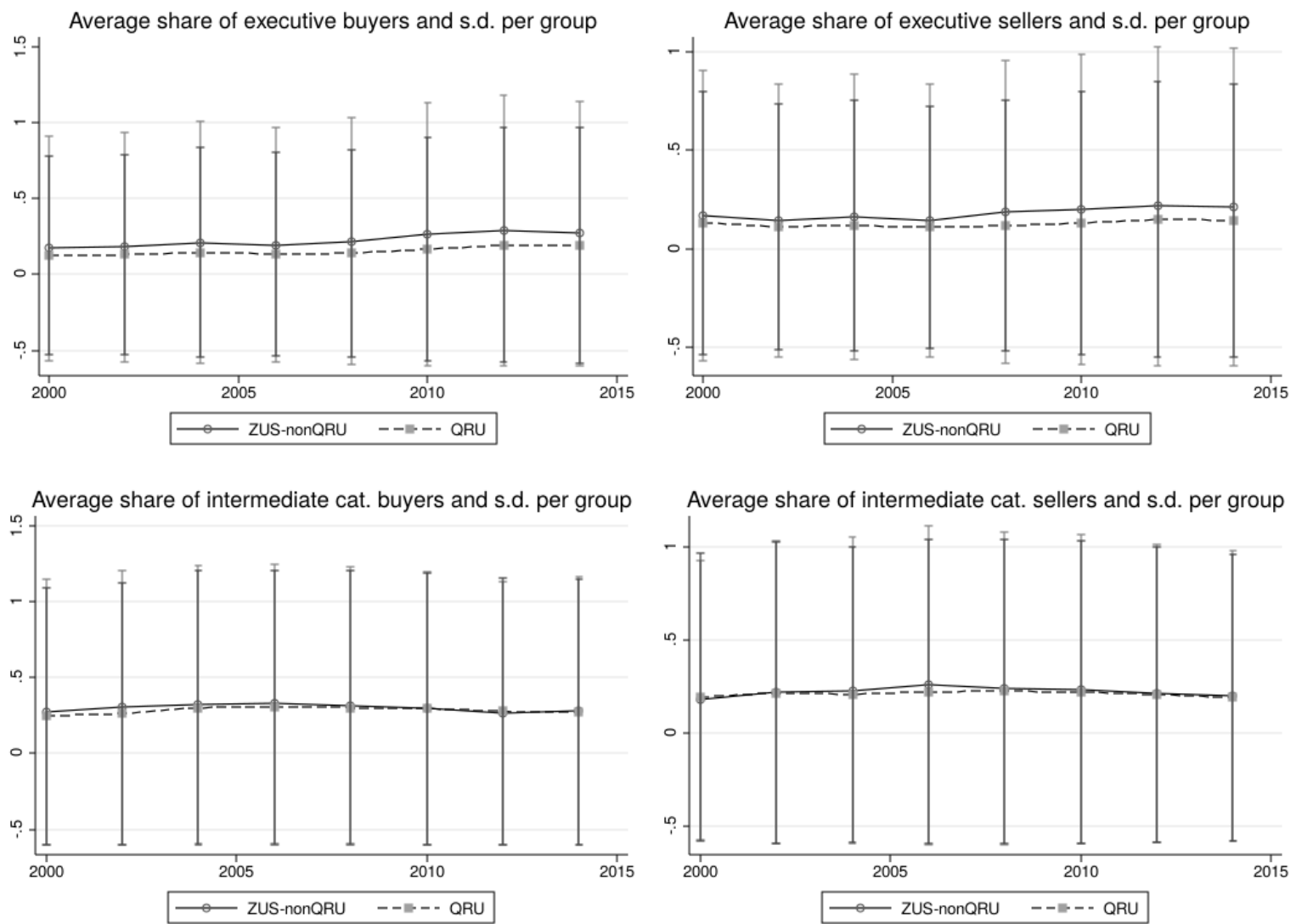

Average share of executive blue-collar buyers and s.d. per grou
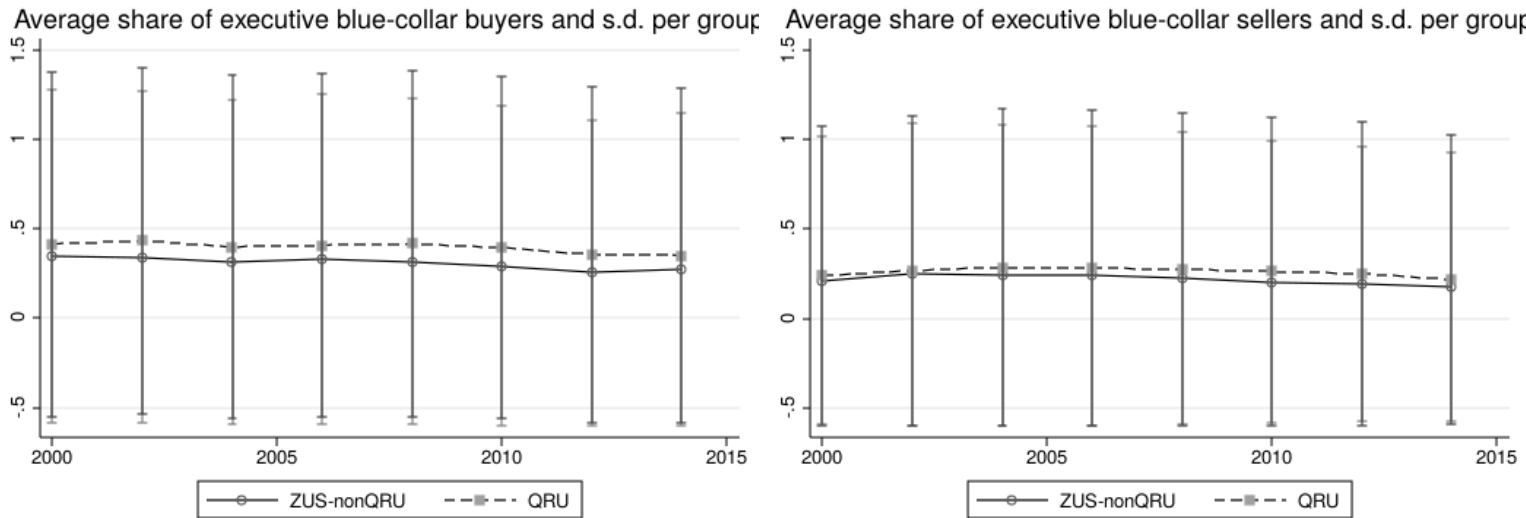

Figure A4: Evolution of the average share of executive buyers (resp. executive sellers, intermediate category buyers and intermediate category sellers, blue-collar buyers, blue-collar sellers, retired buyers, retired sellers) per neighborhood in renovated and non renovated urban policy neighborhoods 
Table A1: Baseline results - Impact of the PNRU program on housing prices (From the left to the right: Progressive introduction of additional explanatory variables)

\begin{tabular}{|c|c|c|c|c|}
\hline & $\begin{array}{c}(1) \\
\text { Neigh.\& yr FE }\end{array}$ & $\begin{array}{c}(2) \\
+ \text { Hsg char. }\end{array}$ & $\begin{aligned} & (3) \\
+ & \text { dist. }\end{aligned}$ & $\begin{array}{c}(4) \\
+\mathrm{UU} \text { trends } \\
\end{array}$ \\
\hline$\beta_{T}$ & $-0.0594^{*}$ & -0.0352 & -0.0348 & 0.00866 \\
\hline \multicolumn{5}{|l|}{ Year of transaction } \\
\hline 2002 & $0.156^{* * *}$ & $0.165^{* * *}$ & $0.165^{* * *}$ & $0.145^{* * *}$ \\
\hline 2004 & $0.501^{* * *}$ & $0.482^{* * *}$ & $0.482^{* * *}$ & $0.419^{* * *}$ \\
\hline 2006 & $0.828^{* * *}$ & $0.810^{* * *}$ & $0.810^{* * *}$ & $0.712^{* * *}$ \\
\hline 2008 & $0.914^{* * *}$ & $0.892^{* * *}$ & $0.892^{* * *}$ & $0.768^{* * *}$ \\
\hline 2010 & $0.910^{* * *}$ & $0.882^{* * *}$ & $0.881^{* * *}$ & $0.723^{* * *}$ \\
\hline 2012 & $0.934^{* * *}$ & $0.908^{* * *}$ & $0.908^{* * *}$ & $0.724^{* * *}$ \\
\hline 2014 & $0.913^{* * *}$ & $0.846^{* * *}$ & $0.846^{* * *}$ & $0.643^{* * *}$ \\
\hline \multicolumn{5}{|c|}{ Dwelling type ${ }^{*}$ number of rooms } \\
\hline Apart.\#1 room & & $-1.697^{* * *}$ & $-1.700^{* * *}$ & $-1.695^{* * *}$ \\
\hline House $\# 1$ room & & $-1.763 * * *$ & $-1.767 * * *$ & $-1.798^{* * *}$ \\
\hline Apart. \#2 rooms & & $-1.078 * * *$ & $-1.080 * * *$ & $-1.082^{* * *}$ \\
\hline House $\# 2$ rooms & & $-0.886^{* * *}$ & $-0.886^{* * *}$ & $-0.888^{* * *}$ \\
\hline Apart. $\# 3$ rooms & & $-0.721^{* * *}$ & $-0.724^{* * *}$ & $-0.725^{* * *}$ \\
\hline House $\# \mathbf{3}$ rooms & & $-0.499 * * *$ & $-0.500 * * *$ & $-0.498 * * *$ \\
\hline Apart.\#4 rooms & & $-0.501 * * *$ & $-0.504^{* * *}$ & $-0.504^{* * *}$ \\
\hline House $\# 4$ rooms & & $-0.217 * * *$ & $-0.218^{* * *}$ & $-0.216^{* * *}$ \\
\hline Apart. $\# 5$ rooms & & $-0.312^{* * *}$ & $-0.314^{* * *}$ & $-0.318^{* * *}$ \\
\hline Less than 5 years old & & 0.0462 & 0.0468 & $0.0616^{* *}$ \\
\hline Floor area per room & & $0.0341^{* * *}$ & $0.0341^{* * *}$ & $0.0341^{* * *}$ \\
\hline \multicolumn{5}{|l|}{ Number of bathrooms } \\
\hline 0 bathroom & & $-0.230 * * *$ & $-0.230 * * *$ & $-0.172^{* * *}$ \\
\hline 2 bathrooms & & $0.102^{* * *}$ & $0.102^{* * *}$ & $0.103^{* * *}$ \\
\hline 3 bathrooms & & $-0.0858^{* * *}$ & $-0.0852^{* * *}$ & $-0.0908^{* * *}$ \\
\hline \multicolumn{5}{|l|}{ Construction period } \\
\hline Const $0-1850$ & & $-0.141 * * *$ & $-0.141 * * *$ & $-0.114^{* * *}$ \\
\hline Const 1851-1913 & & $-0.206^{* * *}$ & $-0.207^{* * *}$ & $-0.170 * * *$ \\
\hline Const 1914-1947 & & $-0.149 * * *$ & $-0.150 * * *$ & $-0.144^{* * *}$ \\
\hline Const 1948-1969 & & $-0.109^{* * *}$ & $-0.110^{* * *}$ & $-0.109^{* * *}$ \\
\hline Const $1970-1980$ & & $-0.0765^{* * *}$ & $-0.0762 * * *$ & $-0.0762 * * *$ \\
\hline Const $1992-2000$ & & $0.0886^{* * *}$ & $0.0882^{* * *}$ & $0.0875^{* * *}$ \\
\hline Const 2001-2010 & & $0.144^{* * *}$ & $0.145^{* * *}$ & $0.138^{* * *}$ \\
\hline Const 2011-2020 & & $0.292^{* * *}$ & $0.297^{* * *}$ & $0.288^{* * *}$ \\
\hline Const unknown & & $-0.0831^{* * *}$ & $-0.0835^{* * *}$ & $-0.0832^{* * *}$ \\
\hline Dist. to urban unit center & & & $-2.69 \mathrm{e}-05^{* * *}$ & $-2.66 \mathrm{e}-05^{* * *}$ \\
\hline Constant & $11.54^{* * *}$ & $11.94^{* * *}$ & $12.08^{* * *}$ & $11.77^{* * *}$ \\
\hline Neighborhood fixed effect & $\mathrm{Y}$ & $\mathrm{Y}$ & $\mathrm{Y}$ & $\mathrm{Y}$ \\
\hline Observations & 72,193 & 72,193 & 72,193 & 72,193 \\
\hline R-squared & 0.513 & 0.824 & 0.824 & 0.844 \\
\hline
\end{tabular}

Notes: Dependent variable is the log price of the housing transaction. Estimation method is OLS. $\beta_{T}$ is the estimated average effect of renovation over the years after renovation started. Explanatory variables are: year and neighborhood fixed effects in Column 1, housing characteristics (interaction term between housing type (apartment or house) and number of rooms, dummy equal to one if the housing unit was constructed less than 5 years before the transaction, dummies for the construction period (Const t1-t2 is equal to 1 if the housing unit was constructed between year t1 and year t2) are added in Column 2, distance to the center of the urban unit is added in Column 3. Quadratic trends at the urban unit level are included in Column 4 but their coefficients are omitted from the table for lack of space. Robust standard errors clustered at the neighborhood level in parentheses. ${ }^{* * *} \mathrm{p}<0.01,{ }^{* *} \mathrm{p}<0.05,{ }^{*} \mathrm{p}<0.1$. 
Table A2: Robustness checks: Alternative clustering and fixed effects' geographical levels - DFE estimator

\begin{tabular}{lcccc}
\hline & $\begin{array}{c}\text { FE neigh. } \\
\text { Cluster neigh. }\end{array}$ & $\begin{array}{c}\text { FE neigh. } \\
\text { Cluster urb. unit }\end{array}$ & $\begin{array}{c}\text { FE neigh. } \\
\text { Cluster IRIS }\end{array}$ & $\begin{array}{c}\text { FE IRIS } \\
\text { Cluster IRIS }\end{array}$ \\
\hline \multirow{2}{*}{$(1)$} & $(2)$ & $(3)$ & $(4)$ \\
$\beta_{T}$ & 0.0105 & $0.0105^{*}$ & 0.0105 & 0.0094 \\
& $(0.0096)$ & $(0.0057)$ & $(0.0067)$ & $(0.0065)$ \\
Observations & 72,193 & 72,193 & & \\
R-squared & 0.847 & 0.847 & 72,193 & 72,193 \\
\hline
\end{tabular}

Notes: Dependent variable is the log price of the housing transaction. Estimation method is OLS. $\beta_{T}$ is the estimated average effect of renovation over the years after renovation started. In Column 1, fixed effects and standard error clustering are at the neighborhood level. In Column 2, fixed effects are at the neighborhood level and standard error clustering at the urban unit level. In Column 3, fixed effects are at neighborhood level and standard error clustering is at the infra-communal IRIS level. In Column 4, fixed effects and standard error clustering are at the infra-communal IRIS level. Explanatory variables included are housing unit characteristics, distance, urban unit time trends and year and neighborhood fixed effects. Robust standard errors clustered at the level indicated in column title in parentheses. ${ }^{* * *} \mathrm{p}<0.01,{ }^{* *} \mathrm{p}<0.05,{ }^{*} \mathrm{p}<0.1$.

Table A3: Robustness checks: Difference-in-differences with propensity score matching or neighborhood weighting - DFE estimator

\begin{tabular}{|c|c|c|c|c|c|c|c|}
\hline & \multicolumn{4}{|c|}{ Propensity score matching } & \multicolumn{3}{|c|}{ Weighting procedure } \\
\hline & \multirow{2}{*}{\multicolumn{2}{|c|}{$\begin{array}{l}\text { Kernel matching } \\
\text { Bandwidth value }\end{array}$}} & \multirow{2}{*}{\multicolumn{2}{|c|}{$\begin{array}{c}\text { Lechner rad. matching } \\
\text { Max weight in } \%\end{array}$}} & \multirow{2}{*}{\multicolumn{2}{|c|}{ Bandwidth value }} & \multirow{3}{*}{$\begin{array}{c}\mathrm{w} / \mathrm{o} 25 \% \\
\text { most distant ZUS } \\
\text { Optimal } \\
(7)\end{array}$} \\
\hline & & & & & & & \\
\hline & $\begin{array}{l}.001 \\
(1)\end{array}$ & $\begin{array}{l}.06 \\
(2)\end{array}$ & $\begin{array}{l}.1 \\
(3)\end{array}$ & $\begin{array}{l}.025 \\
(4)\end{array}$ & $\begin{array}{l}\text { Optimal } \\
(5)\end{array}$ & $\begin{array}{l}2^{*} \text { opt. } \\
\quad(6)\end{array}$ & \\
\hline \multirow[t]{2}{*}{$\beta_{T}$} & 0.0148 & 0.0128 & 0.0145 & 0.0138 & -0.00919 & -0.00450 & 0.00485 \\
\hline & $(0.0115)$ & $(0.0113)$ & $(0.0126)$ & $(0.0129)$ & $(0.0167)$ & $(0.0133)$ & $(0.00953)$ \\
\hline Obs. & 71,785 & 71,936 & 69,937 & 59,988 & 71,868 & 72,141 & 70,758 \\
\hline R-squared & 0.850 & 0.846 & 0.844 & 0.851 & 0.844 & 0.849 & 0.846 \\
\hline
\end{tabular}

Notes: Dependent variable is the log price of the housing transaction. Estimation method is OLS. $\beta_{T}$ is the estimated average effect of renovation over the years after renovation started. In Columns 1 and 2, kernel propensity score matching is used in a preliminary step before the OLS regression, with a bandwidth of 0.001 in Column 1 and 0.06 in Column 2. In Columns 3 and 4 Lechner's radius matching method is used in a preliminary step, with a maximum weight per transaction of $0.1 \%$ of the sample size in Column 3 and of $0.025 \%$ of the sample size in Column 4 . In Columns 5 to 7, neighborhoods are weighted in a preliminary step, using Silverman (1986)'s methodology, with a bandwidth set at the optimal level in Column 5 and at twice the optimal level in Column 6 . In Column 7 , the $25 \%$ of non renovated neighborhoods, which estimated probability to be renovated is the most distant from the proportion of renovated urban policy neighborhoods, are suppressed from the sample. All the remaining transactions are given a weight equal to 1 . Explanatory variables included are housing unit characteristics, distance, urban unit time trends and year and neighborhood fixed effects. Robust standard errors clustered at the neighborhood level in parentheses. $* * * \mathrm{p}<0.01, * * \mathrm{p}<0.05, * \mathrm{p}<0.1$. 
Table A4: Robustness checks - Propensity score estimation

\begin{tabular}{|c|c|}
\hline Logit model & $\begin{array}{l}\text { Explained variable: } \\
\text { Probability for the transaction to be } \\
\text { located in a renovated neighborhood }\end{array}$ \\
\hline \multicolumn{2}{|l|}{ Neighborhood characteristics } \\
\hline Relative share of social housing & $1.096^{* * *}$ \\
\hline Relative share of owners & $2.917^{* * *}$ \\
\hline Relative share of unemployed & $9.912^{* * *}$ \\
\hline Relative revenue & $-12.75^{* * *}$ \\
\hline Squared relative share of social housing & $-0.210^{* * *}$ \\
\hline Squared relative share of owners & $-1.180^{* * *}$ \\
\hline Squared relative share of unemployed & $-3.939 * * *$ \\
\hline Squared relative revenue & $4.044^{* * *}$ \\
\hline Floor area per room & $0.0144^{* * *}$ \\
\hline \multicolumn{2}{|l|}{ Dwelling type } \\
\hline House & $0.0908 * * *$ \\
\hline \multicolumn{2}{|l|}{ Number of rooms } \\
\hline 1 room & $-0.455^{* * *}$ \\
\hline 2 rooms & $-0.218^{* * *}$ \\
\hline 4 rooms & -0.0413 \\
\hline$\geq 5 \mathrm{rooms}$ & 0.0324 \\
\hline \multicolumn{2}{|l|}{ Number of bathrooms } \\
\hline 0 bathroom & -0.0907 \\
\hline 2 bathrooms & -0.0647 \\
\hline Nb of bathrooms unknown & 0.0507 \\
\hline \multicolumn{2}{|l|}{ Period of construction } \\
\hline Const $0-1850$ & $-0.692^{* * *}$ \\
\hline Const 1851-1913 & $-0.980 * * *$ \\
\hline Const 1914-1947 & 0.0227 \\
\hline Const 1948-1969 & $0.117^{* * *}$ \\
\hline Const $1970-1980$ & $0.403^{* * *}$ \\
\hline Const 1992-2000 & $0.176^{* *}$ \\
\hline Const 2001-2010 & $0.369^{* * *}$ \\
\hline Const 2011-2020 & $0.928 * * *$ \\
\hline Const unknown & $0.140^{* * *}$ \\
\hline Constant & $1.142^{* * *}$ \\
\hline Observations & 72,142 \\
\hline
\end{tabular}

Notes: Propensity score estimation used for propensity score matching in Table A3. Dependent variable is a dummy equal to 1 if the transaction is located in a renovated neighborhood and 0 if it is not. The estimation method is a logit model. The "relative share of social housing" corresponds to the share of social housing in the neighborhood, as compared to the average share of social housing in the urban policy neighborhoods of the urban unit. The other "relative" variables are computed in a similar fashion. "House" is a dummy equal to 1 if the transacted housing unit is a house (instead of an apartment). "X rooms" is a dummy equal to 1 if the transacted housing unit has X rooms (the effect on price is estimated in comparison to a 3-room housing unit). "X bathrooms" is a dummy equal to 1 if the transacted housing unit has $\mathrm{X}$ bathrooms (the effect on price is estimated in comparison to a 1-bathroom housing unit). "Const t1-t2" is a dummy equal to 1 if the housing unit was built between year t1 and year t2 (the effect on price is estimated in comparison to the period of construction 1981-1991). $* * * \mathrm{p}<0.01,{ }^{* *} \mathrm{p}<0.05,{ }^{*} \mathrm{p}<0.1$. 
Table A5: Robustness checks - Propensity score - Comparison of treated and control group transactions before and after matching

\begin{tabular}{|c|c|c|c|c|c|c|}
\hline \multirow[b]{3}{*}{ Variable } & \multicolumn{3}{|c|}{ Unmatched } & \multicolumn{3}{|c|}{ Matched } \\
\hline & \multicolumn{2}{|c|}{ Mean } & \multirow[b]{2}{*}{ \%bias } & \multicolumn{2}{|c|}{ Mean } & \multirow[b]{2}{*}{ \%bias } \\
\hline & Treated & Control & & Treated & Control & \\
\hline \multicolumn{7}{|c|}{ Housing unit characteristics } \\
\hline House & 16178 & .12644 & 10.1 & .17176 & .23567 & -18.2 \\
\hline Floor space per room & 21.069 & 21.159 & -1.6 & 21.03 & 21.485 & -8.4 \\
\hline 1 room & .08054 & .11962 & -13.0 & .08177 & .06788 & 4.6 \\
\hline 2 rooms & .18266 & .22942 & -11.6 & .18551 & .15461 & 7.7 \\
\hline 3 rooms & .28573 & .26486 & 4.7 & .28085 & .26642 & 3.2 \\
\hline 4 rooms & .28304 & .24986 & 7.5 & .28287 & .29857 & -3.6 \\
\hline 5 rooms & .16803 & .13625 & 8.9 & .169 & .21252 & -12.1 \\
\hline 1 bathroom & .02178 & .02957 & -4.9 & .02216 & .02117 & 0.6 \\
\hline 2 bathrooms & .88666 & .87707 & 3.0 & .88615 & .86806 & 5.6 \\
\hline 3 bathrooms & .0431 & .04163 & 0.7 & .04212 & .05471 & -6.3 \\
\hline 4 bathrooms & .04846 & .05173 & -1.5 & .04957 & .05606 & -3.0 \\
\hline \multicolumn{7}{|l|}{ Building period } \\
\hline$<1850$ & .00522 & .01827 & -12.1 & .00595 & .00513 & 0.8 \\
\hline $1850-1913$ & .0491 & .11563 & -24.4 & .05759 & .03482 & 8.3 \\
\hline $1914-1947$ & .10261 & .09356 & 3.0 & .10911 & .09794 & 3.8 \\
\hline 1948-1969 & .23386 & .22548 & 2.0 & .23766 & .20686 & 7.3 \\
\hline $1970-1980$ & .27443 & .2012 & 17.3 & .25307 & .26782 & -3.5 \\
\hline 1981-1991 & .05424 & .0624 & -3.5 & .05408 & .07771 & -10.1 \\
\hline $1992-2000$ & .02078 & .02606 & -3.5 & .02186 & .02646 & -3.0 \\
\hline $2001-2010$ & .01469 & .01442 & 0.2 & .01503 & .02187 & -5.7 \\
\hline $2011-2020$ & .00467 & .00226 & 4.1 & .00476 & .00685 & -3.6 \\
\hline Unknown & .24039 & .24072 & -0.1 & .24089 & .25455 & -3.2 \\
\hline \multicolumn{7}{|c|}{ Neighborhood characteristics in 1999} \\
\hline rel. \% social housing & 1.0595 & 0.85316 & 39.5 & 1.0295 & 1.1407 & -21.3 \\
\hline$(\text { rel. \% social housing })^{2}$ & 1.3798 & 1.0161 & 22.8 & 1.3131 & 1.5905 & -17.4 \\
\hline rel. \% homeowners & .96856 & 1.0776 & -32.3 & .99223 & .91777 & 22.0 \\
\hline$(\text { rel. \% homeowners })^{2}$ & 1.0272 & 1.3004 & -34.4 & 1.0758 & .94209 & 16.8 \\
\hline rel. \% unemployed & 1.0482 & .88103 & 90.9 & 1.0055 & .99783 & 4.2 \\
\hline$(\text { rel. \% unemployed })^{2}$ & 1.1358 & .80679 & 84.3 & 1.0363 & 1.0246 & 3.0 \\
\hline rel. mean income & .94862 & 1.1268 & -102.0 & .98667 & .99384 & -4.1 \\
\hline$(\text { rel. mean income })^{2}$ & .92757 & 1.3031 & -101.1 & .99314 & 1.0078 & -3.9 \\
\hline
\end{tabular}

Notes: Comparison of treated and control group transactions before and after the matching procedure corresponding to Column 4 of Table A3 (Lechner's procedure with maximum weight 0.025). The mean of each explanatory variable before matching in the treated (resp. in the control) group is reported in Column 2 (resp. 3). A measure of the bias between treated and control group on this variable is displayed in Column 4. The three last columns (5 to 7) are similar to Columns 2 to 4 , except that the mean and bias are computed after matching. Among the explanatory variables, "House" is a dummy equal to 1 if the transacted housing unit is a house (instead of an apartment), "X rooms" is a dummy equal to one if the housing unit has exactly X rooms, "rel. \% social housing" corresponds to the relative share of social housing in the neighborhood's housing stock as compared to the average share of social housing in the urban policy neighborhoods of the urban unit to which the neighborhood in question belongs. When all bias measures are smaller than $10 \%$, it is generally agreed that treated and control groups are comparable. 
Balanced panel of neighborhoods

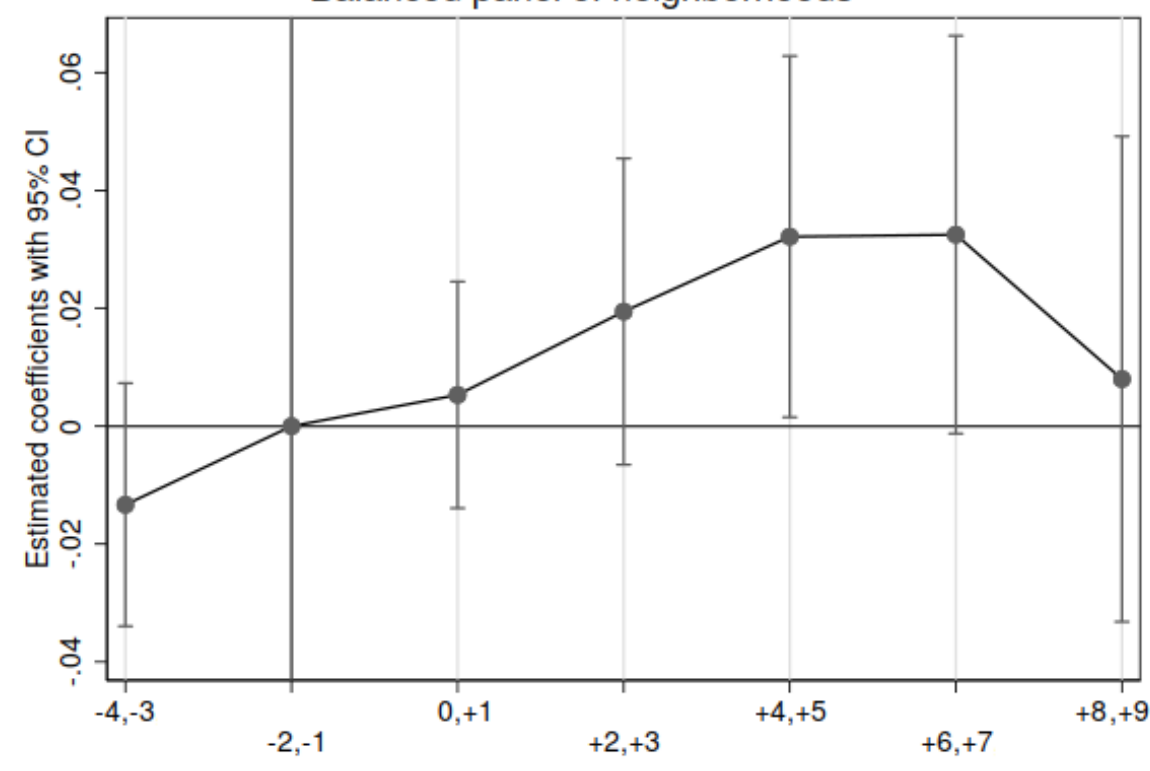

Figure A5: Robustness checks: Impact of the PNRU program on housing prices estimated with a balanced panel of neigborhoods, i.e. keeping only renovated neighborhoods where renovation started in 2004 or 2005 and restricting the sample to time-varying effects comprised between $(-4,-3)$ and $(+8,+9)$. 


\section{DFE method}

Seller executlve - buyer executlve

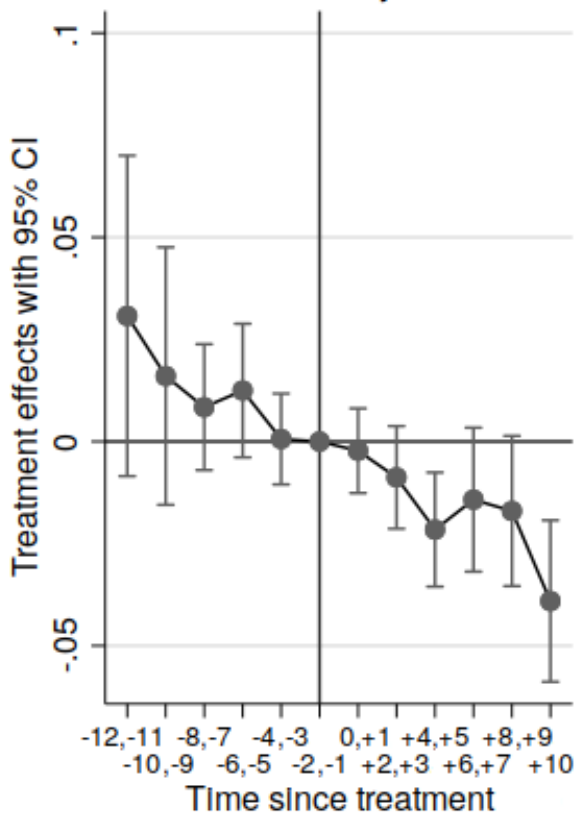

Seller blue collar - buyer Intermedlate categ.

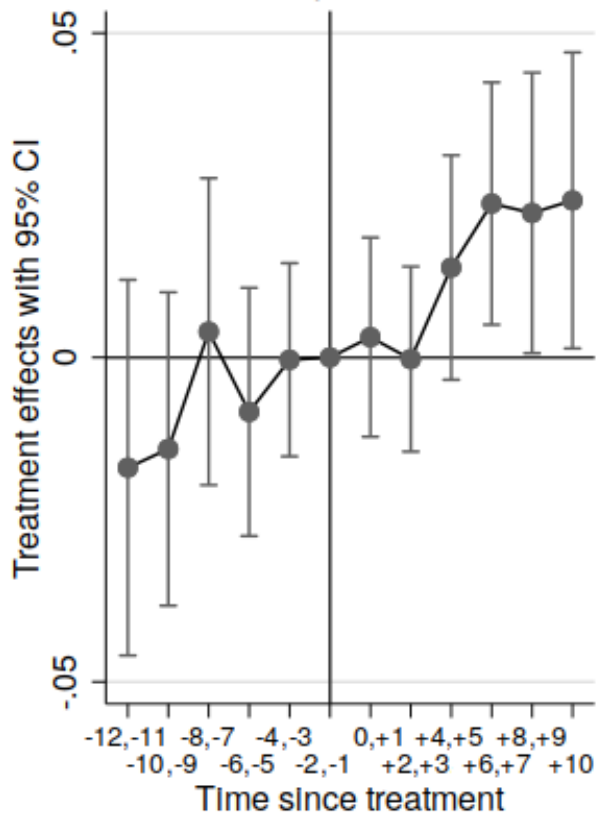

Seller Intermedlate categ. - buyer executlve

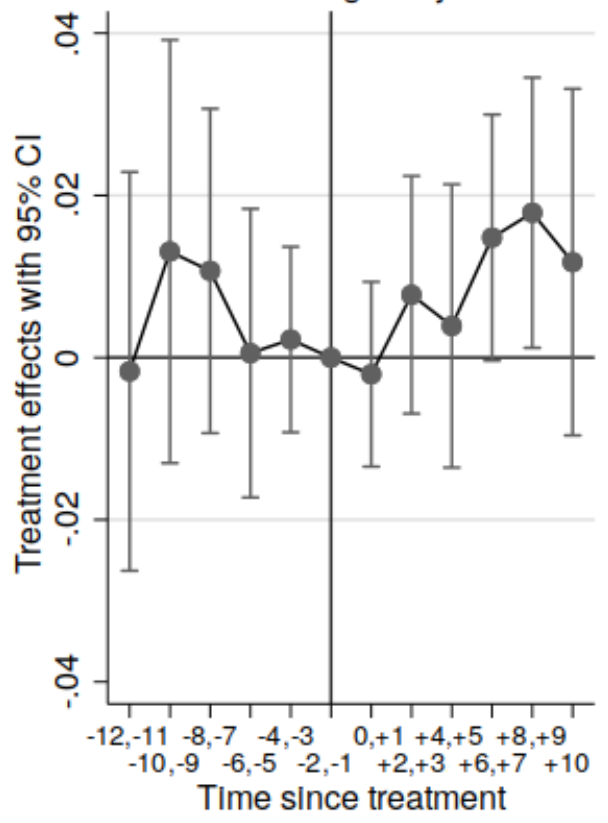

Figure A6: DFE pre-trends and time-varying treatment effects on transitions probabilities in the four largest cities. Robust standard errors clustered at the neighborhood level. 